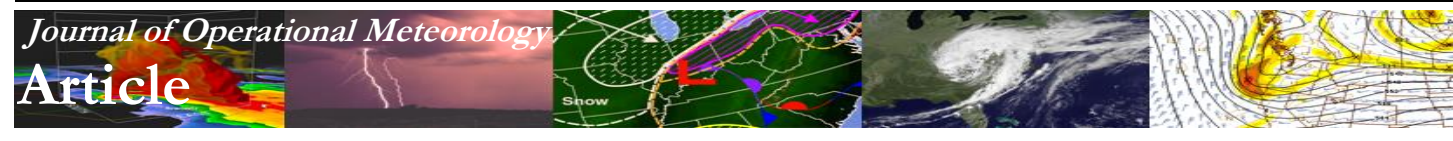

\title{
A Historical Analog-Based Severe Weather Checklist for Central New York and Northeastern Pennsylvania
}

\author{
MICHAEL S. EVANS and RON A. MURPHY \\ National Weather Service, Johnson City, New York \\ (Manuscript received 24 February 2014; review completed 16 May 2014)
}

\begin{abstract}
This paper describes an operational severe weather checklist developed at the National Weather Service Forecast Office (WFO) in Binghamton, New York (BGM). The checklist contains a traditional severe weather parameter data entry section and a historical analog retrieval section. Parameters on the checklist are related to the synoptic weather pattern, stability, vertical wind shear, and moisture. The analog retrieval portion of the checklist returns information on five historical events that are analogous to current conditions, based on data entered into the checklist. An example of the utility of the checklist is shown for a major severe weather event on 28 April 2011 that featured numerous severe weather reports (including seven tornadoes) in the WFO BGM county warning area. The top analog retrieved by the checklist for this case was associated with 17 tornadoes, and another analog featured three tornadoes.

Results from a verification study on the similarity between 81 test events and corresponding analogs are shown. High correlations were found between values of convective available potential energy and bulk shear in the test cases versus corresponding values of those parameters in the analogs. A comparison of radar imagery and severe weather reports associated with the test cases and corresponding analogs indicates that the system can help forecasters anticipate convective mode and discriminate between major and null severe events. The system also provides useful guidance on the potential for tornadoes and convective flash flooding, and may help forecasters decide whether events will be dominated by wind or hail.
\end{abstract}

\section{Introduction}

Previous research has demonstrated that a thorough assessment of the prestorm environment is a critical step in the severe weather warning process. Knowledge of the environment allows forecasters to anticipate the evolution and magnitude of severe convective events (Weisman and Klemp 1984; Brooks et al. 1994; Dial et al. 2010; Lombardo and Colle 2010; Thompson et al. 2012). Many meteorological parameters have been developed over the past several decades to help forecasters with this assessment; these parameters are related primarily to basic atmospheric characteristics such as forcing for vertical motion, stability, and vertical wind shear (Rasmussen 2003; Craven and Brooks 2004; Doswell and Schultz 2006). Continued research and software development has led to the increased availability of these parameters to operational meteorologists over the past several decades.
Severe weather checklists have been developed, in part, to help forecasters organize the large quantity of information contained within these parameters. Checklists have been around since at least the 1950s when the concept of severe weather parameters was first introduced (Fawbush and Miller 1954). Subsequent research has resulted in development of new parameters and conceptual models, which have been utilized to update and improve checklists (e.g., Evans and Murphy 2008; Troutman et al. 2009; Wheeler 2009; Gordon and Albert 2012). Typically, values for these checklists are obtained from observed or modelforecast soundings, which have been used widely to forecast severe storms for many decades (Beebe 1958; Thompson et al. 2003). An important consideration when applying these checklists is that they should not be used in isolation but should be applied as part of an ingredients-based methodology (Doswell et al. 1996;

Corresponding author address: Michael S. Evans, Binghamton Weather Forecast Office, 32 Dawes Drive, Johnson City, NY 13790 E-mail: michael.evans@noaa.gov 
Wetzel and Martin 2001), including application of scientifically based conceptual models. Output from high-resolution numerical models, which are becoming more widely used operationally, also should be examined (Kain et al. 2006, 2008). Finally, forecaster experience and pattern recognition should be a critical component of the severe weather forecasting process (Johns and Doswell 1992; Hart and Grumm 2001).

One way for forecasters to assess severe weather potential based on pattern recognition is through the use of historical analogs. Researchers at Saint Louis University have developed guidance for significant weather events based on comparisons between forecast data and historical analogs (Gravelle et al. 2009). Likewise, the Storm Prediction Center (SPC) has developed a sounding analog retrieval system, which is an analog-matching system that compares a current or forecast sounding to a database of historical proximity soundings (Jewell 2010). The system produces probabilistic forecasts of severe weather phenomena based on occurrences of severe weather associated with the best historical analogs.

This paper will demonstrate an application developed at the National Weather Service Forecast Office (WFO) in Binghamton, New York (BGM), that combines many of the attributes of a severe weather checklist with a historical analog retrieval system. Section 2 introduces the application, which includes both a traditional checklist component and an analog retrieval component. Section 3 shows an example of how the application can be used operationally. Section 4 shows results from a verification study of output from the application, and section 5 contains a summary and conclusion.

\section{The checklist}

\section{a. A standard online checklist}

The checklist was designed for forecasters assessing severe weather potential in the WFO BGM county warning area (CWA), which is comprised of central New York and northeastern Pennsylvania (Fig. 1). Forecasters who open the WFO BGM severe weather checklist application are first presented with a standard online checklist, including several parameters that are commonly used to assess severe weather potential (Fig. 2). The parameters were chosen based on consideration of a wide range of relevant published research (e.g., LaPenta et al. 2002), analyses from numerous locally developed case studies, and availability of the data via local software and online sources such

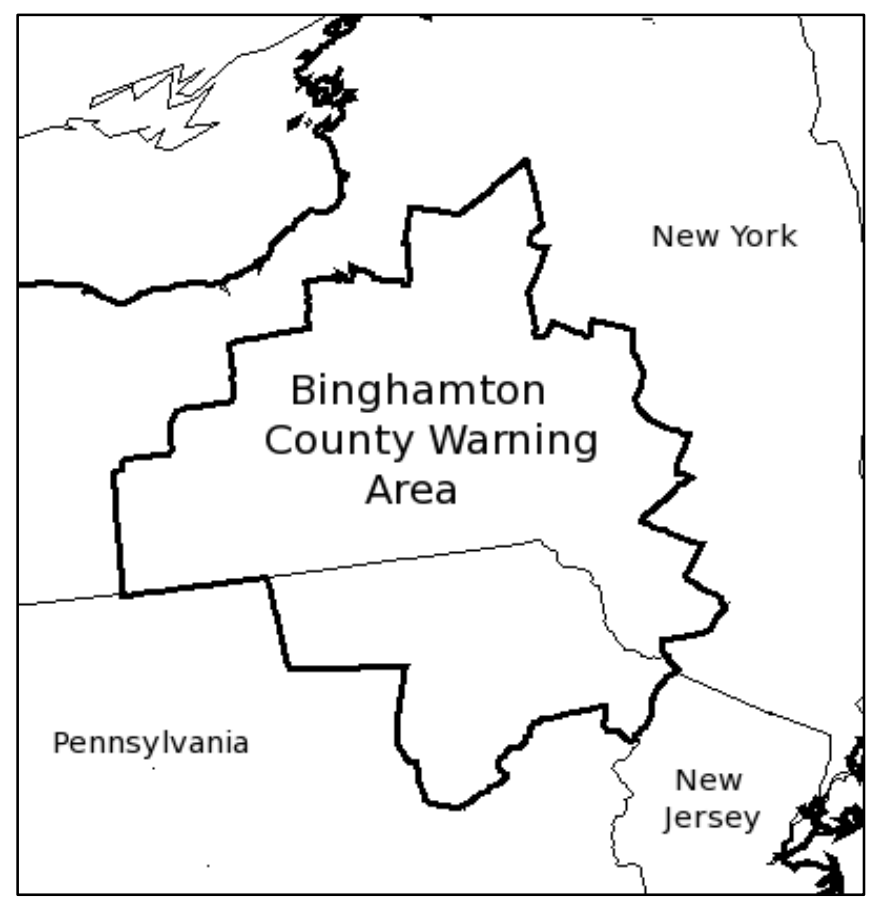

Figure 1. A map of the WFO BGM county warning area. Click image for an external version; this applies to all figures hereafter.

\begin{tabular}{|c|c|c|c|}
\hline \begin{tabular}{|l|l|} 
Patanneters \\
\end{tabular} & Entry & References & Where to find \\
\hline Surface Weather Pattems = & Progessive Cold fiont $\sim v$ & (2) & ? \\
\hline $\begin{array}{l}12 \text { hour } 500 \text { mb height falls }(\mathrm{m})= \\
\text { Values of falling heights should be positive. }\end{array}$ & 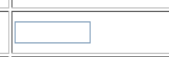 & (2) & ? \\
\hline Mive Layer CAPE $=$ & $\square$ & (2) & ? \\
\hline $\mathrm{CIN}=$ & $\square$ & (2) & ? \\
\hline Lapse Rate 950 to $700 \mathrm{mb}(\mathrm{c} / \mathrm{hrn})=$ & $\square$ & (2) & ? \\
\hline Lapse rate 700 to $500 \mathrm{mb}(\mathrm{c} / \mathrm{cm})=$ & $\square$ & (2) & ? \\
\hline $\begin{array}{l}\begin{array}{l}\text { Mavimum Dewpoint Depression } \\
\text { from 700-500 mb }(c)=\end{array} \\
\end{array}$ & $\square$ & (2) & ? \\
\hline 0.1 kn Helicity $=$ & $\square$ & (2) & ? \\
\hline $0-1$ kn bull shear (in knots) $=$ & $\square$ & (2) & ? \\
\hline $0.3 \mathrm{~km}$ bulk shear (in knots) $=$ & $\square$ & (2) & ? \\
\hline 0.6 km bulls shear (in knots $)=$ & $\square$ & (2) & ? \\
\hline $0.3 \mathrm{knd}$ directional shear vector (in degress) $=$ & $\mid \square$ & (2) & ? \\
\hline EL stom relative flow (knots) = & $\square$ & (2) & ? \\
\hline Enter the Precipitable Water (inches) & 1 & (2) & ? \\
\hline Enter the Soli Moisture. & $\mid \square$ & (2) & ? \\
\hline
\end{tabular}

Figure 2. The data entry page of the WFO BGM severe weather checklist.

as the SPC mesoanalysis website (www.spc.noaa.gov/ exper/mesoanalysis/) and BUFfalo toolKIT (BUFKIT) software (Mahoney and Niziol 1997). The parameters can be divided into four main categories: (i) surface 
frontal and geopotential height characteristics (the surface weather pattern and $12-\mathrm{h} 500-\mathrm{hPa}$ geopotential height falls); (ii) stability [mixed-layer (surface-500$\mathrm{m})$ convective available potential energy (CAPE), convective inhibition (CIN), and 950-700- and 700-500$\mathrm{hPa}$ lapse rates]; (iii) vertical wind shear (bulk shear calculated for the $0-1-\mathrm{km}, 0-3-\mathrm{km}$, and $0-6-\mathrm{km}$ layers, $0-1-\mathrm{km}$ storm-relative helicity (SRH), and equilibrium-level storm-relative flow); and (iv) moisture (700-500-hPa maximum dewpoint depression, precipitable water, and soil moisture). Although arguments certainly can be made for inclusion of additional parameters, the number of parameters chosen represented a compromise between making the list as comprehensive as possible without making its completion overly cumbersome. Completion of the checklist helps forecasters organize their assessment of the convective environment and also helps facilitate shift briefings.

Forecasters are encouraged to derive values for these parameters from whatever source they feel is most appropriate, including model forecast soundings, modification of upstream observed soundings, and current observations. The WFO BGM CWA does not include an upper-air site, so model forecast soundings often play a key role in completion of the checklist. Typically, values are entered for times and locations corresponding to potential severe weather occurrence. These times often, but not always, correspond to times when CAPE is close to being maximized on area model forecast soundings.

In addition to places for entering values corresponding to each parameter, the data entry portion of the checklist also contains links to helpful information (Fig. 2). For example, the "?" icons in the "References" column point to information on each parameter, including the scientific basis for inclusion of the parameter and the severe weather thresholds based on national and local research. The "?" icons under the "Where to find?" column point to information on where forecasters can find appropriate values to enter. Finally, links are provided at the bottom of the data entry page for access to previously completed checklists (for the purpose of event reviews and case studies) and to a "long checklist," which contains informational links on additional parameters.

\section{b. The analog retrieval component}

After completing the checklist and selecting the "Click me" button at the bottom of the data entry portion of the application (Fig. 2), the forecaster will see the output page from the analog retrieval component of the checklist (Fig. 3). A table at the top of the page contains a list of five historical analog dates, based on similarity between the values entered on the previous page and values stored in a local severe weather events database. The events in the database are comprised of cases that occurred from 2003 to 2013, plus one major event that occurred on 31 May 1998. As of September 2013, the database contained 269 events.
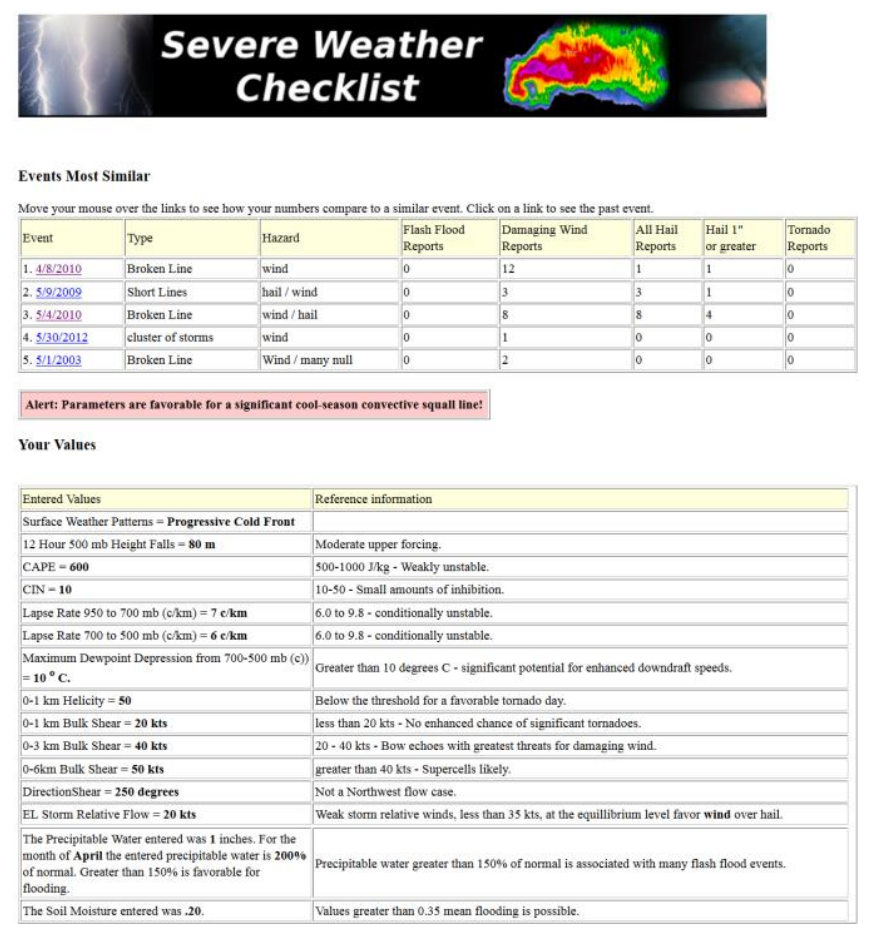

Figure 3. A screen view of the primary output page of the analog retrieval portion of the checklist.

Similarity between the input event and events in the database is determined by a point system. Each event in the database is tested as a potential analog, and events associated with the most points are returned as analogs. Gravelle et al. (2009) stated that analogs can be determined statistically by pattern correlation, mean absolute error, root-mean-square error, or anomalies. Points in this system are determined primarily based on the mean absolute error or the numerical difference between the values of parameters associated with observed events versus the values of parameters associated with each potential analog. For some parameters over some ranges, a ratio between the observed and analog values is calculated to determine point values. Finally, "bonus" points are given if parameter values associated with the observed event and 
potential analog both exceed certain thresholds determined by local or national research to be significant indicators of potential severe weather. For example, a threshold of $2000 \mathrm{~J} \mathrm{~kg}^{-1}$ is utilized for CAPE, based on unpublished local research on highly impactful, warmseason squall lines in the BGM CWA. Likewise, a threshold of $150 \mathrm{~m}^{2} \mathrm{~s}^{-2}$ is utilized for $0-1-\mathrm{km} \mathrm{SRH}$ based on national research (Thompson et al. 2003). Full details on the point system are provided in appen$\operatorname{dix}$ A.

Values in the database are derived from 0-6-h model forecasts from the Rapid Refresh (RAP; Benjamin et al. 2007) since 2011, the Rapid Update Cycle (RUC; Benjamin et al. 2004) for 2006-2009, the 12km North American Mesoscale (NAM; Rogers et al. 2001) for 2003-2006, and the 32-km Eta stepped-terrain model (Black 1994) in 1998. Forecast sounding data are from locations close to each day's maximum concentration of severe weather reports. The profiles are quality controlled to ensure representativeness, including a check to remove soundings with convective contamination. More details on the database are provided in Evans (2010). An important consideration when using the application is that all events in the database are associated with $\geq 1$ report of severe weather or flash flood occurrence. Therefore, regardless of what values are entered into the checklist, all analogs that are returned will be associated with at least one severe weather report and/or at least one flash flood report. However, many events in the database can be considered as "nearly null" cases, as many were associated with only one or two reports. In addition, some of these reports were $1.91-\mathrm{cm}(0.75 \mathrm{in})$ diameter hail (considered severe in the Eastern Region of the National Weather Service prior to 2010), which were not counted as severe weather reports in the verification portion of this study.

Each event in the table is represented by a link in the "Event" column on the far left. Placing the mouse over a link associated with an event displays a table comparing the values of each input parameter with corresponding values associated with the historical analog (Fig. 4). Clicking the link opens another page containing detailed information on the historical event, including a radar reflectivity animation with a brief text summary of the analog (Fig. 5) and model forecast soundings (Figs. 6 and 7).

Forecasters quickly can assess whether a certain mode of convection is favored given the current forecast, based on the values listed in the "Type" column in the table shown in Fig. 3. The "Type" for each

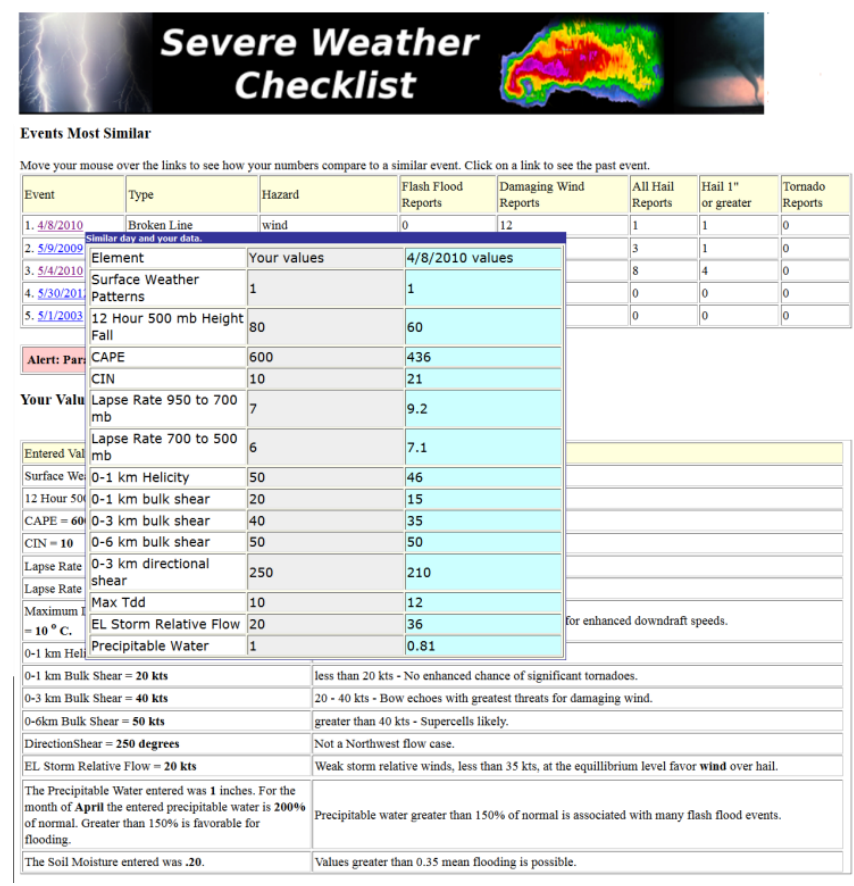

Figure 4. As in Fig. 3, except a screen view of a table comparing entered values to values associated with a selected analog.

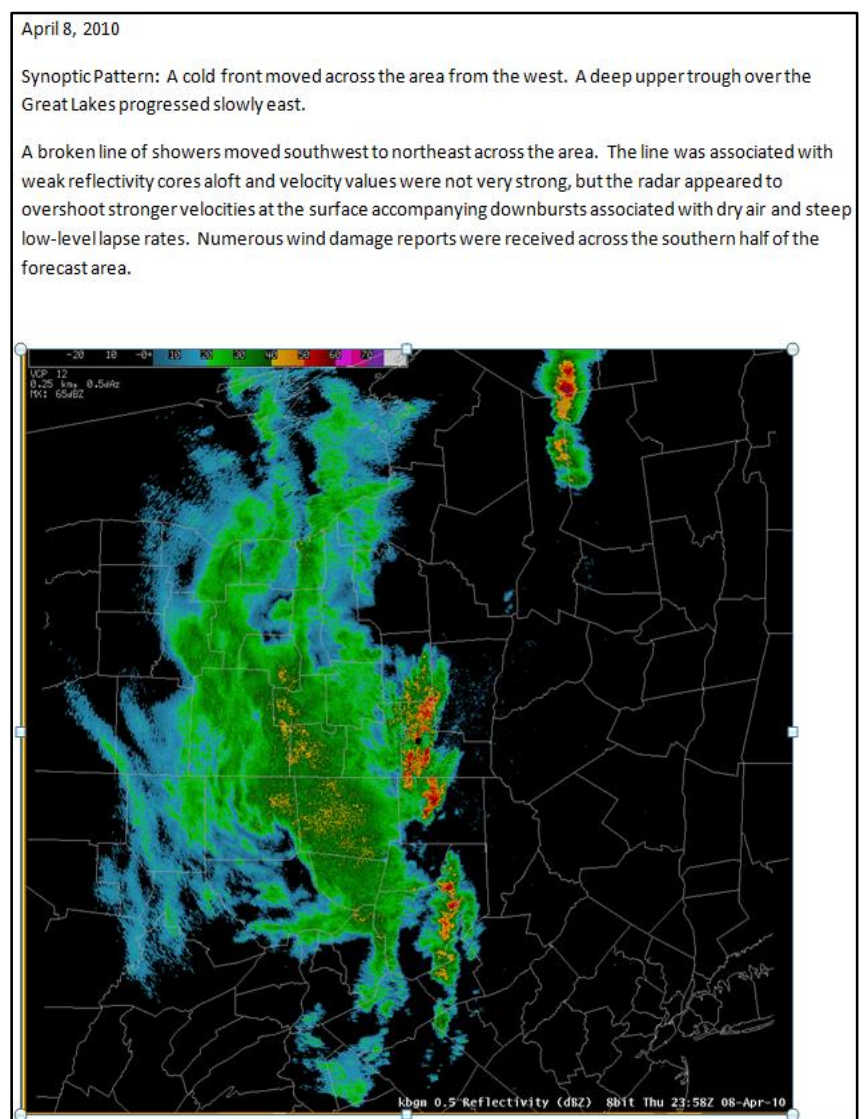

Figure 5. As in Fig. 3, except a screen view of a radar reflectivity image and an associated text discussion from an analog. 


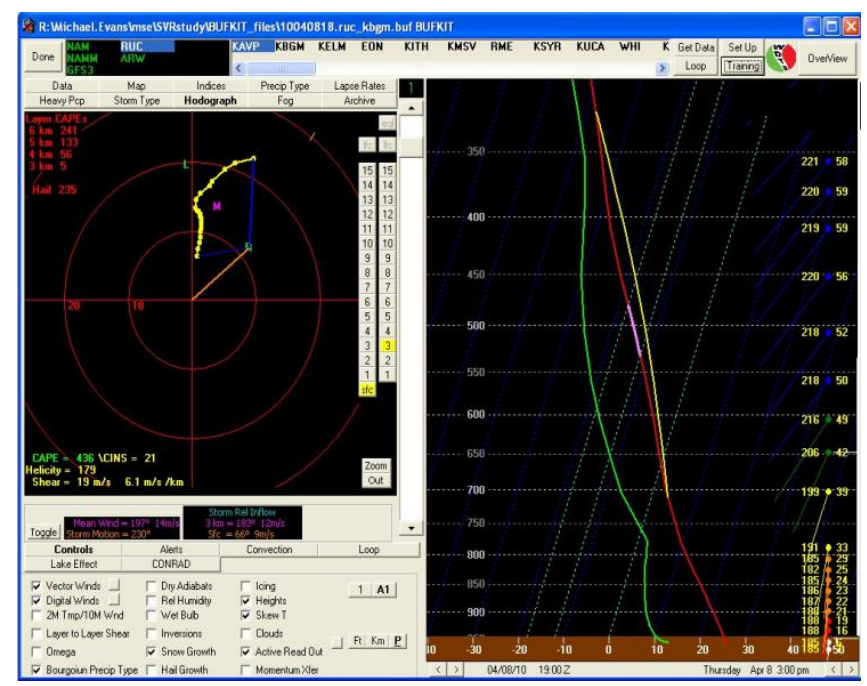

Figure 6. As in Fig. 3, except a screen view of a proximity sounding associated with an analog, including a hodograph (left) and thermal and moisture profiles (right).

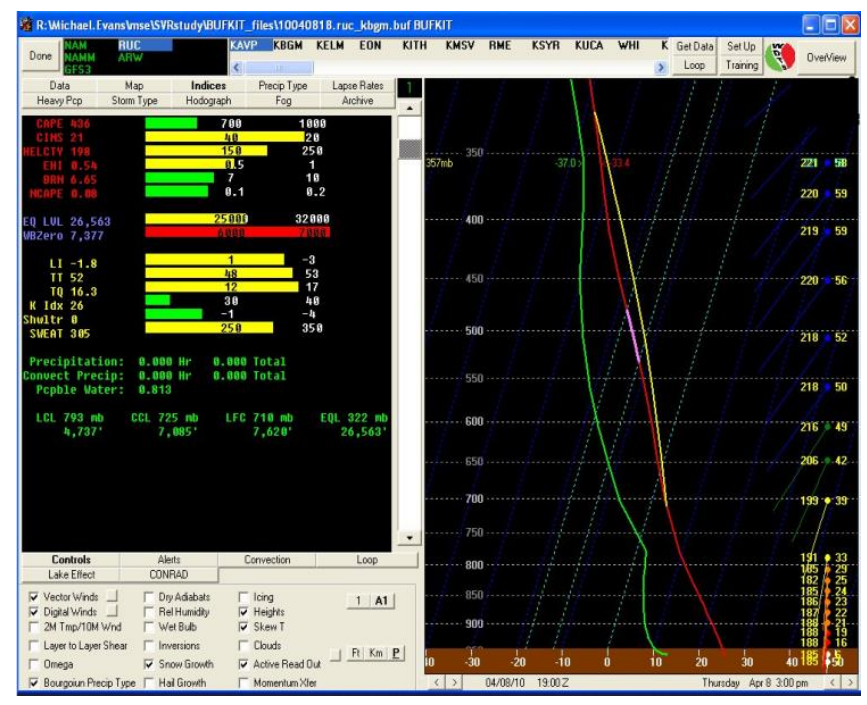

Figure 7. As in Fig. 6, except that the hodograph is replaced by a display listing values of several parameters and indices associated with the sounding on the right.

historical event is determined subjectively based on examination of radar animations. In some cases, several different convective modes may be indicated in the table. However, when a single mode is dominant (Fig. 3 ), the forecaster can gain increased confidence in that outcome. The columns to the right of "Type" indicate the primary hazard associated with each analog event, along with the number of reports from each type. Based on this information, forecasters quickly can determine whether similar historical events have been associated with a large number of severe weather reports and which types of severe reports have been most common.
A red banner will appear beneath the historical analog table if the input parameters meet certain thresholds for geopotential height tendency, surface weather pattern, stability, and shear-as determined from local studies (details are shown in appendix B). The three possible banners are "Alert: parameters are favorable for a significant cool-season convective squall line," "Alert: parameters are favorable for a significant warm-season convective squall line," and "Alert: parameters are favorable for tornadic supercells." Finally, below any banner is a table summarizeing the forecaster's entered values, along with information on the relevance of the entered values.

\section{Example-28 April 2011}

A severe weather outbreak occurred across the northern mid-Atlantic region during the early morning of 28 April 2011 as a cold front tracked east from the Great Lakes toward the East Coast (Fig. 8). This event was part of a historic outbreak of tornadoes that affected the eastern United States on 27-28 April 2011. The mid-to-upper tropospheric flow was highly amplified over the eastern United States early on the 28th, with a strong jet stream oriented from the lower Mississippi Valley to the eastern Great Lakes. Pennsylvania and southern New York were in the right entrance region of a $250-\mathrm{hPa}$ jet streak over the eastern Great Lakes (Fig. 9). The 500-hPa flow was southwesterly and diffluent over the northern mid-Atlantic region, with a strong short-wave trough tracking northeast from the Ohio Valley (Fig. 10). At the surface, Pennsylvania and New York were well to the east of an approaching cold front, with unseasonably high temperatures ranging from 18 to $23^{\circ} \mathrm{C}\left(64\right.$ to $\left.74^{\circ} \mathrm{F}\right)$, dewpoints ranging from 15 to $19^{\circ} \mathrm{C}\left(59\right.$ to $\left.67^{\circ} \mathrm{F}\right)$ and south to southeasterly flow (Fig. 11). The 0000 UTC Pittsburgh (KPIT) sounding on 28 April 2011 indicated modest lapse rates and minimal CAPE across southwestern Pennsylvania. However, the wind magnitude was quite large, with 20.6-25.7- $\mathrm{m} \mathrm{s}^{-1}$ (40-50-kt) winds indicated through a deep layer above $0.5 \mathrm{~km}$ (2000 ft) AGL (Fig. 12). Model forecast soundings, valid several hours later for northeastern Pennsylvania and central New York, indicated that some destabilization would occur within this air mass as it was transported northeastward in the strong southwesterly flow. For example, a 0 -h RUC forecast sounding valid at 0900 UTC at Avoca, Pennsylvania (AVP, located in northeastern Pennsylvania), indicated CAPE of $908 \mathrm{~J}$ $\mathrm{kg}^{-1}$ and a lifted index of $-3^{\circ} \mathrm{C}$ (Fig. 13). A cap was 


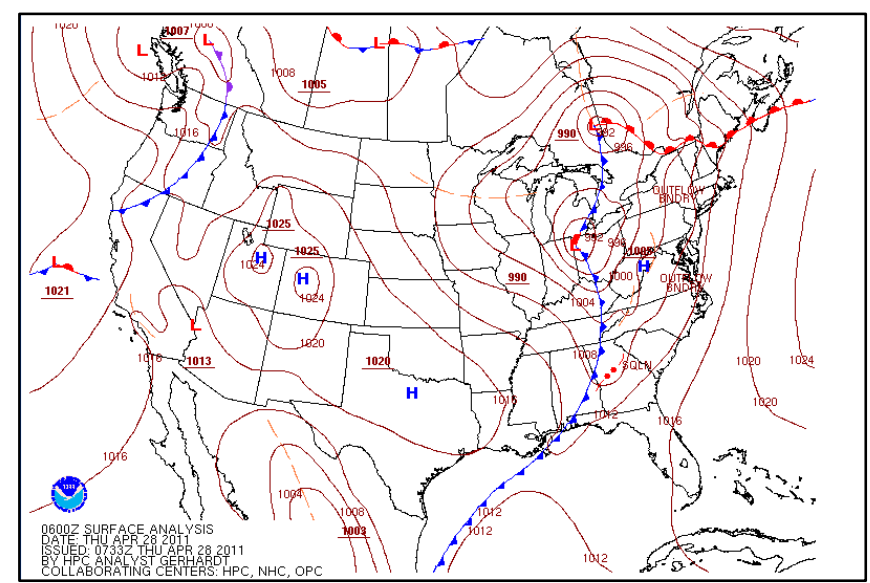

Figure 8. Objective surface analysis valid 0600 UTC 28 April 2011. Image courtesy of the National Centers for Environmental Prediction's Weather Prediction Center.

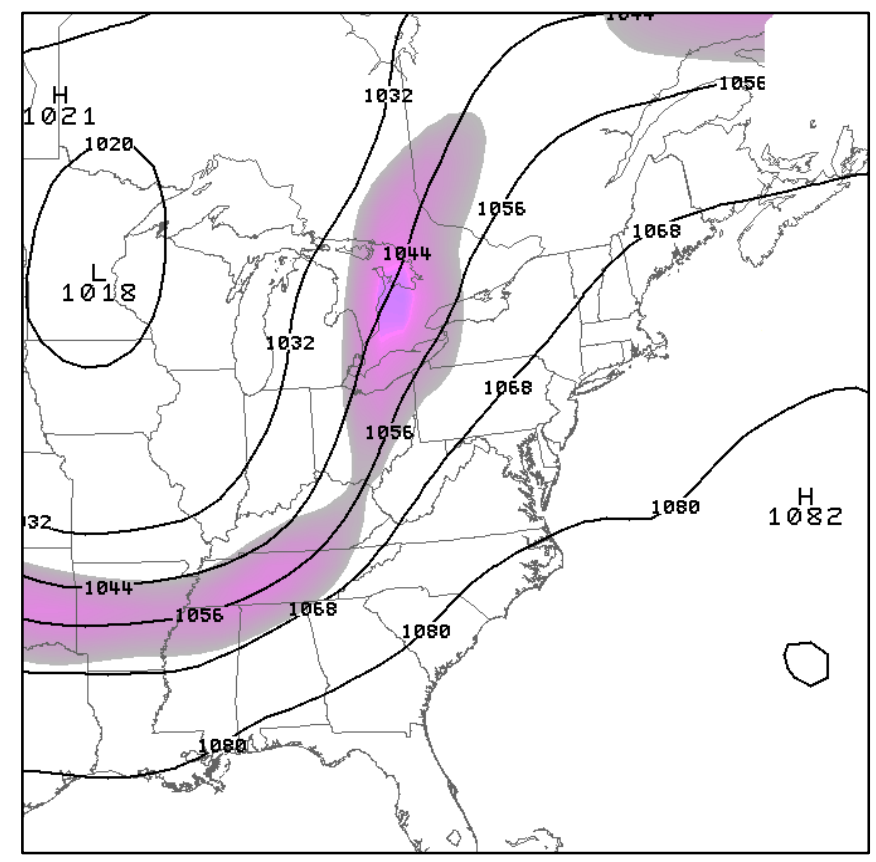

Figure 9. A 6-h NAM forecast of 250-hPa geopotential heights (dam) and wind speed (kt, values $>100$ shaded) valid 0600 UTC 28 April 2011. Multiply values in kt by 0.5144 to obtain $\mathrm{m} \mathrm{s}^{-1}$.

located around $800 \mathrm{hPa}$; however, steep lapse rates were shown above the cap from 800 to $650 \mathrm{hPa}$. Wind magnitudes were even larger than at KPIT, with values $>30.9 \mathrm{~m} \mathrm{~s}^{-1}(60 \mathrm{kt})$ at and above $850 \mathrm{hPa}$.

A completed severe weather checklist based on the RUC forecast sounding valid at 0900 UTC at AVP and the surface pressure and $500 \mathrm{hPa}$ geopotential height pattern described above is shown in Fig. 14. These values can be expected to vary slightly, depending on exactly what data are used in the entry process. Nevertheless, local experience indicates that when multiple

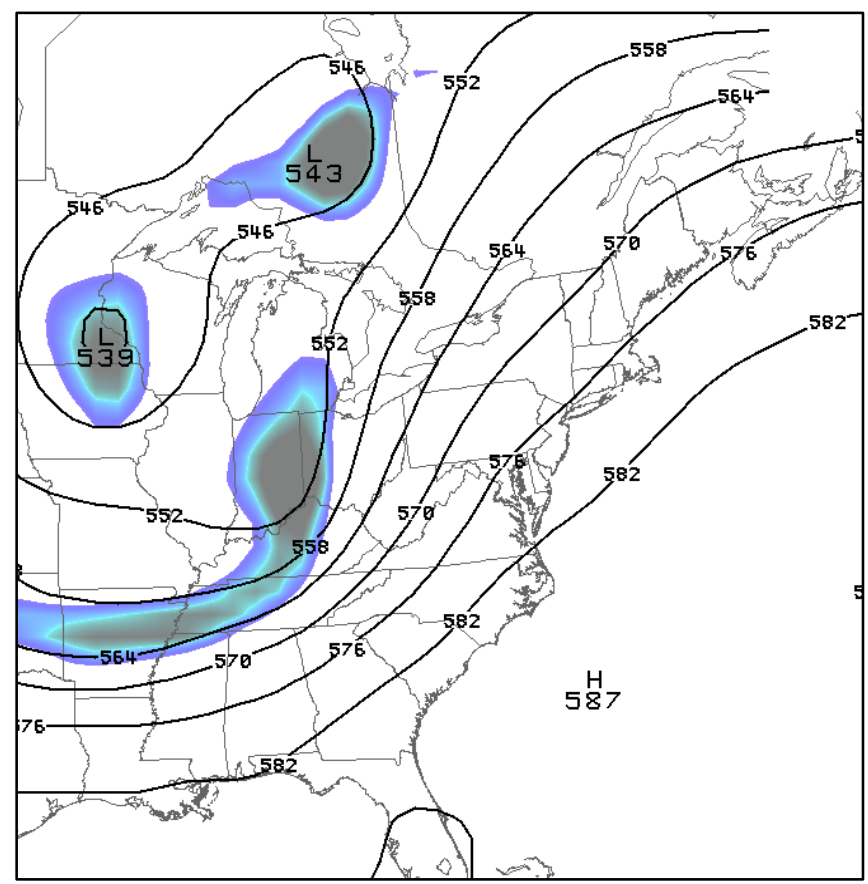

Figure 10. A 6-h NAM forecast of 500-hPa geopotential heights (dam) and vorticity $\left(1 \times 10^{-5} \mathrm{~s}^{-1}\right.$, values $>20$ shaded $)$ valid 0600 UTC 28 April 2011.

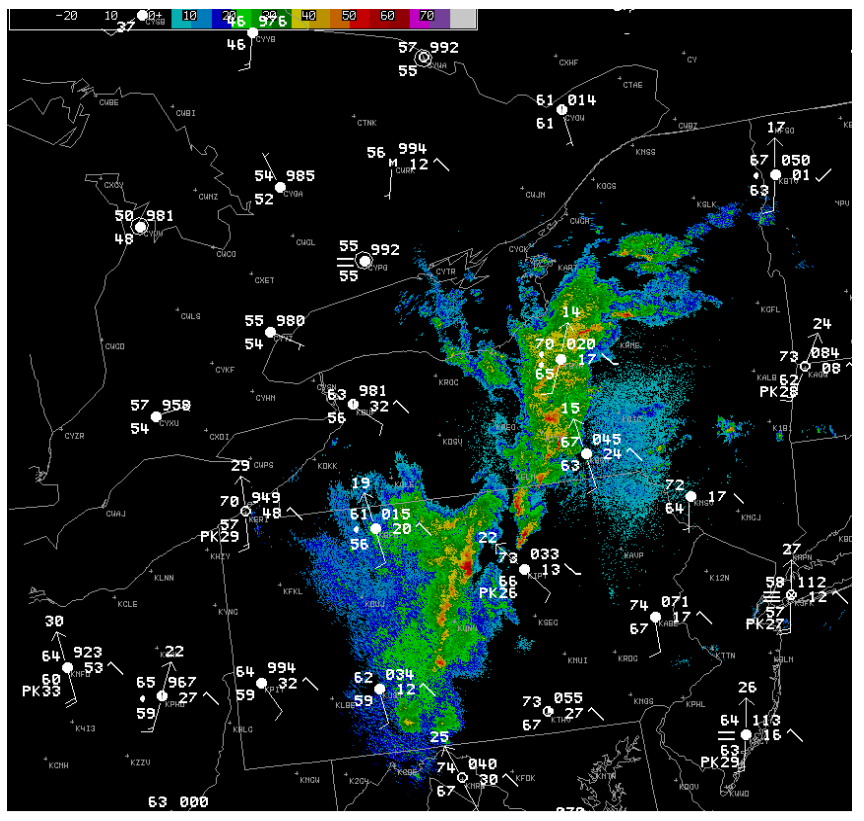

Figure 11. A surface plot and Weather Service Radar-1988 Doppler (WSR-88D) $0.5^{\circ}$ reflectivity mosaic at 0600 UTC 28 April 2011.

forecasters fill out the checklist independently, input values typically do not vary greatly. The key characteristics associated with this event were a progressive cold front with moderately large mid-tropospheric geopotential height falls, modest instability, very strong 


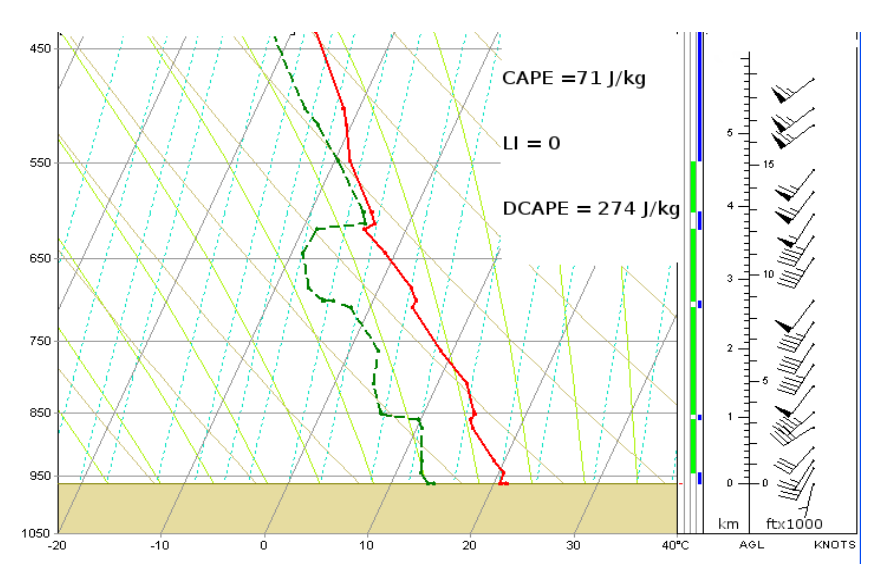

Figure 12. An observed KPIT sounding at 0000 UTC 28 April 2011.

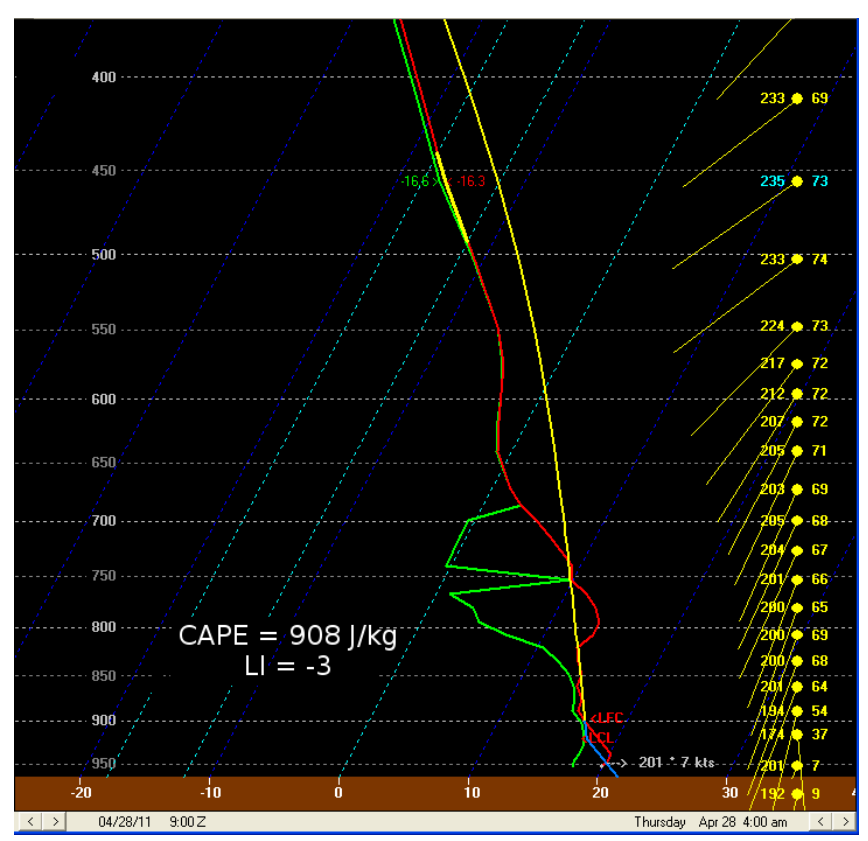

Figure 13. A 0-h RUC forecast sounding at Avoca, PA, valid 0900 UTC 28 April 2011. The red line is the temperature profile, the green line is the dewpoint profile, and the yellow line is a parcel path originating from the $0-500-\mathrm{m}$ mixed layer.

winds with large values of vertical wind shear, and high values of SRH in the 0-1-km layer.

The historical analogs associated with this case are shown in the table in Fig. 15. The first or "best" analog was 31 May 1998 - a massive severe weather event that included 17 tornadoes in the BGM CWA, which is more tornadoes than any other event in the historical database. Note that, as part of a verification study (described in more detail in the next section), the checklist was run for 81 cases for 2011-2013, and this was the only event that returned the 31 May 1998 analog. In addition, the third analog was associated with multiple tornadoes. Given that only $13 \%$ of all of the

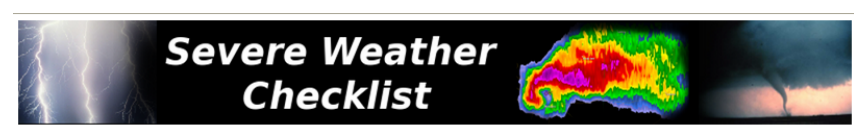

\begin{tabular}{|c|c|c|c|}
\hline Parameters & Entry & References & Where to find? \\
\hline Surface Weather Pattems = & Proglessive Cold Front $\sim$ & (2) & ? \\
\hline $\begin{array}{l}12 \text { hout } 500 \mathrm{mb} \text { height falls }(\mathrm{m})= \\
\text { Values of falling heights should be positive. }\end{array}$ & $\square$ & (2) & ?] \\
\hline Mixed Layer CAPE = & $\square$ & (2) & ? \\
\hline $\mathrm{CIN}=$ & $\square$ & (2) & ? \\
\hline Lapse Rate 950 to $700 \mathrm{mb}(\mathrm{c} / \mathrm{km})=$ & $\square$ & (2) & ?] \\
\hline Lapse rate 700 to $500 \mathrm{mb}(\mathrm{c} / \mathrm{hm})=$ & $\square$ & (2) & ? \\
\hline $\begin{array}{l}\text { Maximum Dewpoint Depression } \\
\text { from } 700-500 \mathrm{mb}(c)=\end{array}$ & $\square$ & (2) & ? \\
\hline $0-1 \mathrm{~km}$ Helicity = & $\square$ & (2) & ? \\
\hline $0-1$ kn bulk shear (in knots) $=$ & $\square$ & (2) & ?] \\
\hline 0.3 kn bulk shear (in knots) $=$ & $\square$ & (2) & ?] \\
\hline $0.6 \mathrm{~km}$ bullk shear (in knots) = & $\square$ & (2) & ? \\
\hline $0-3 \mathrm{~km}$ directional shear vector (in degrees) $=$ & $\square$ & (2) & ?] \\
\hline EL storm relative flow (knots) = & $\square$ & (2) & ? \\
\hline Enter the Precipitable Water (inches) & 1.53 & (2) & ?] \\
\hline Enter the Soil Moisture. & $\square$ & (2) & [?] \\
\hline
\end{tabular}

Figure 14. A completed data entry portion of the checklist for the 28 April 2011 severe weather event for northern PA and southern NY.

\section{Severe Weather Checklist}

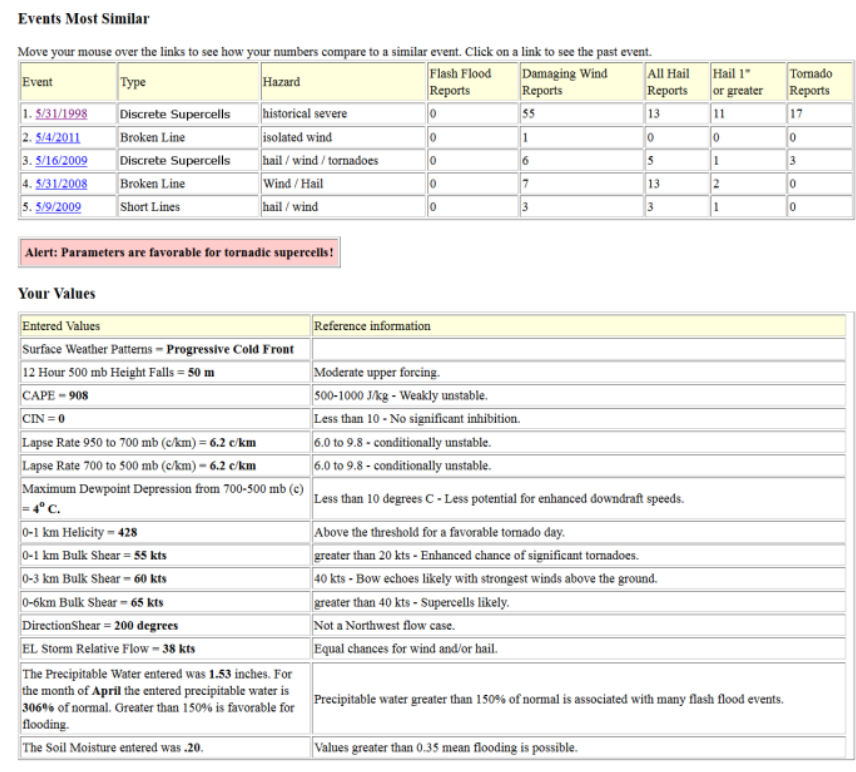

Figure 15. The output page from the analog retrieval portion of the checklist for the 28 April 2011 severe weather event. The first five analogs are displayed in the table at the top of the page. A summary of entered parameter values and corresponding severe weather thresholds is shown at the bottom.

events in the historical database include tornadoes, the fact that the analogs for this case included events with multiple tornadoes would be an indication that torna- 
does would be a significant concern on 28 April 2011. The convective mode associated with the analogs was a mixture of discrete supercells and linear modes, indicating no strong preference for any specific evolution.

Placing the mouse over the link associated with the best analog allowed the user to directly compare parameters from 28 April 2011 with parameters from the analog (Fig. 16). Most of the key parameters in this example appeared to be a good match, with $0-1-\mathrm{km}$ shear and SRH actually larger on 28 April 2011 than on 31 May 1998. Finally, clicking the link corresponding to the date of the analog displays radar and forecast sounding data from the analog (Figs. 17, 18, and 19). The best analog featured a mixture of discrete supercells and short linear segments, making the case somewhat difficult to classify. However, the majority of the tornadoes occurred with discrete supercells. Therefore, the case was classified as a discrete supercell event.
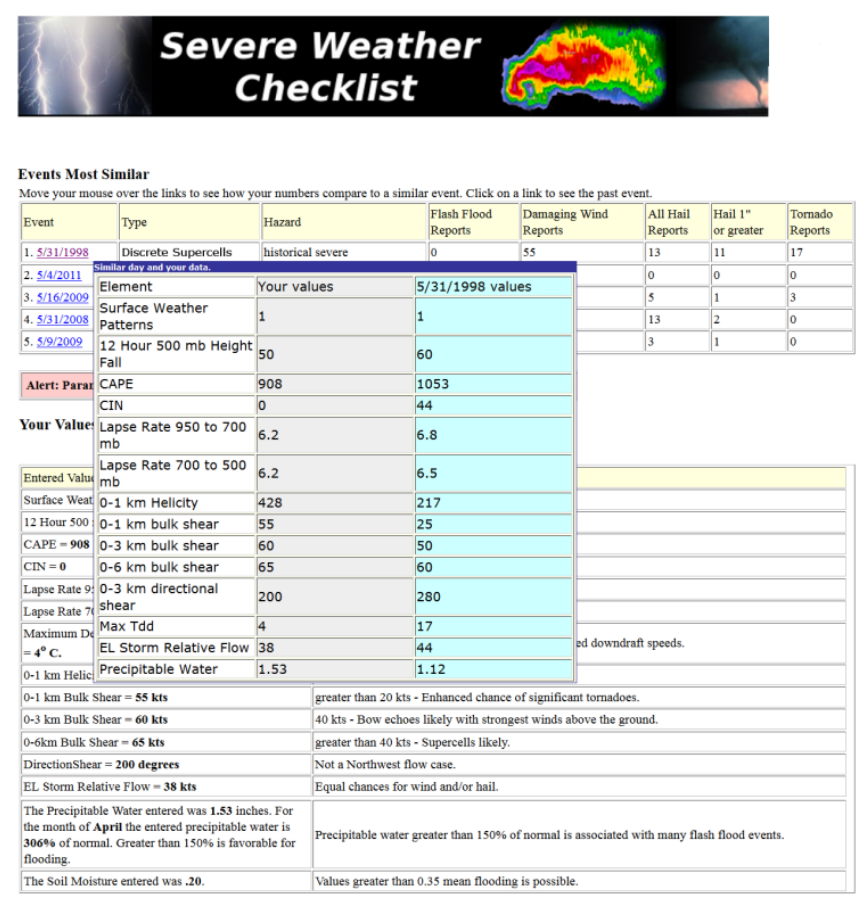

Figure 16. A table comparing input parameter values to values from the first analog for 28 April 2011.

A widespread severe weather event occurred on 28 April 2011, including seven tornadoes in the BGM CWA. Twenty-eight flash floods also were reported in the BGM CWA, despite the fact that no flash floods were indicated on the analogs. Tornadoes initially developed in association with discrete supercells over central New York (Fig. 20). However, the discrete cells eventually were overtaken by a line of convec-
May 31, 1998

Synoptic Pattern: A strong cold front moved across the area with strong low-mid level winds and moderately strong height falls.

Massive, historical severe weather outbreak, with 17 tornadoes including 4 rated as F3. Over 50 damaging wind reports and several large hail reports up to golf ball size.

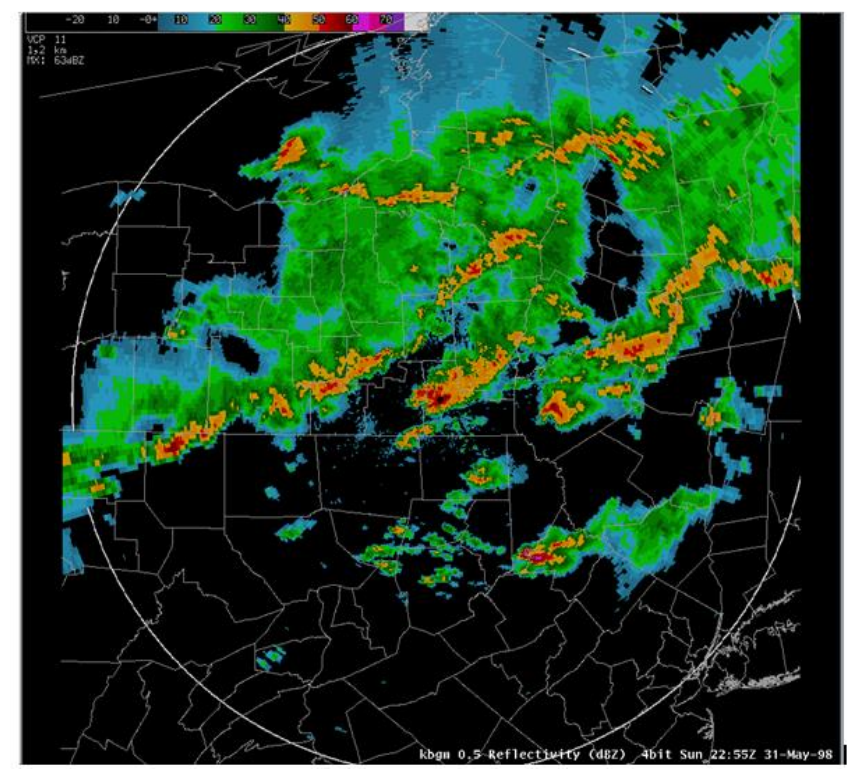

Figure 17. An image of radar reflectivity data at 2255 UTC 31 May 1998 from the first analog; associated text discussion at top.

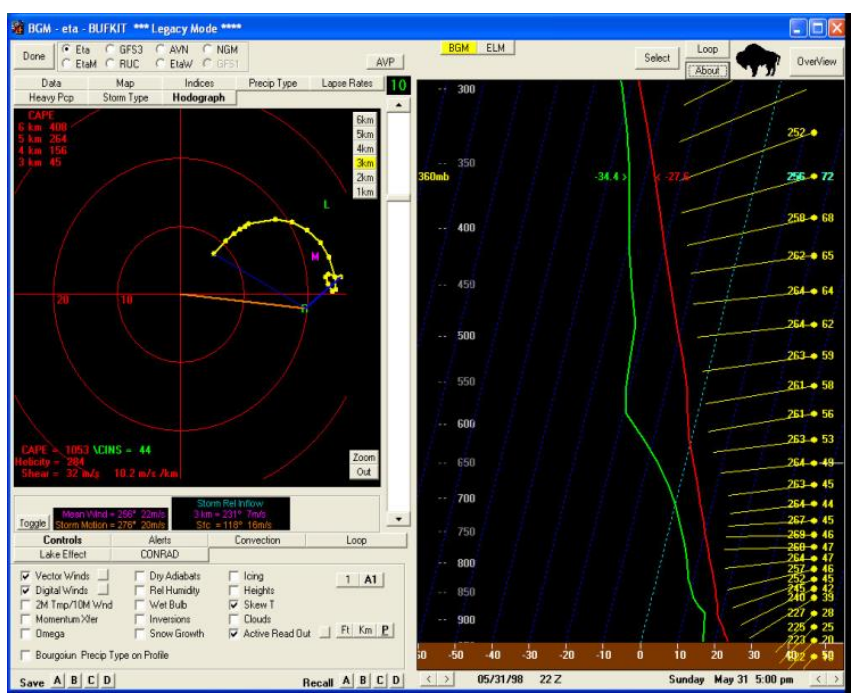

Figure 18. A proximity sounding, including a hodograph and a thermal profile, associated with the first analog.

tion, which was associated mainly with damaging straight-line winds and flash flooding (Fig. 21). This case illustrates the difficulty that often occurs when trying to classify the dominant convective mode of an event. In this case, the event was classified as "discrete supercell" because six of the seven tornadoes occurred with discrete supercells. 


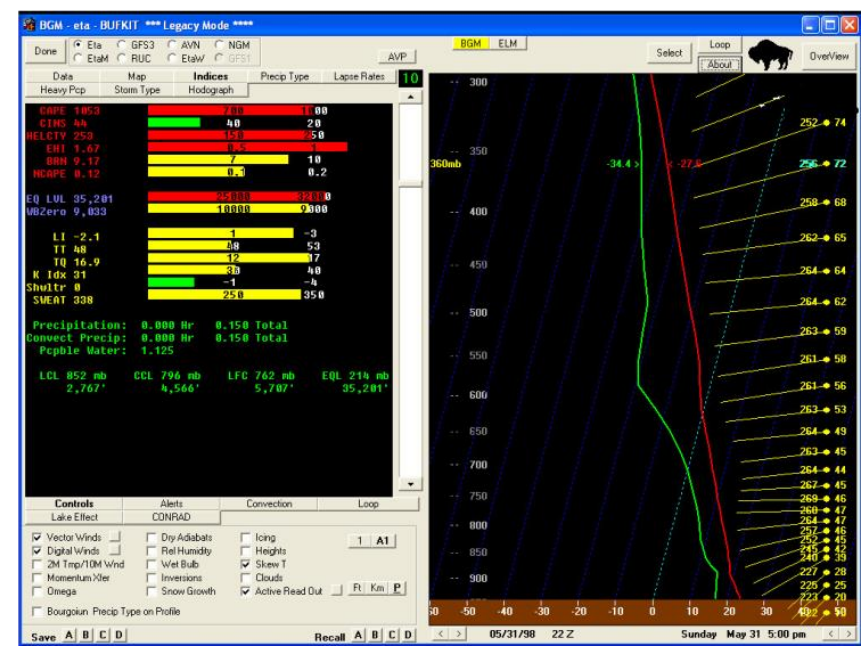

Figure 19. As in Fig. 18, except that the hodograph is replaced by a display listing values of several parameters and indices associated with the profile on the right.

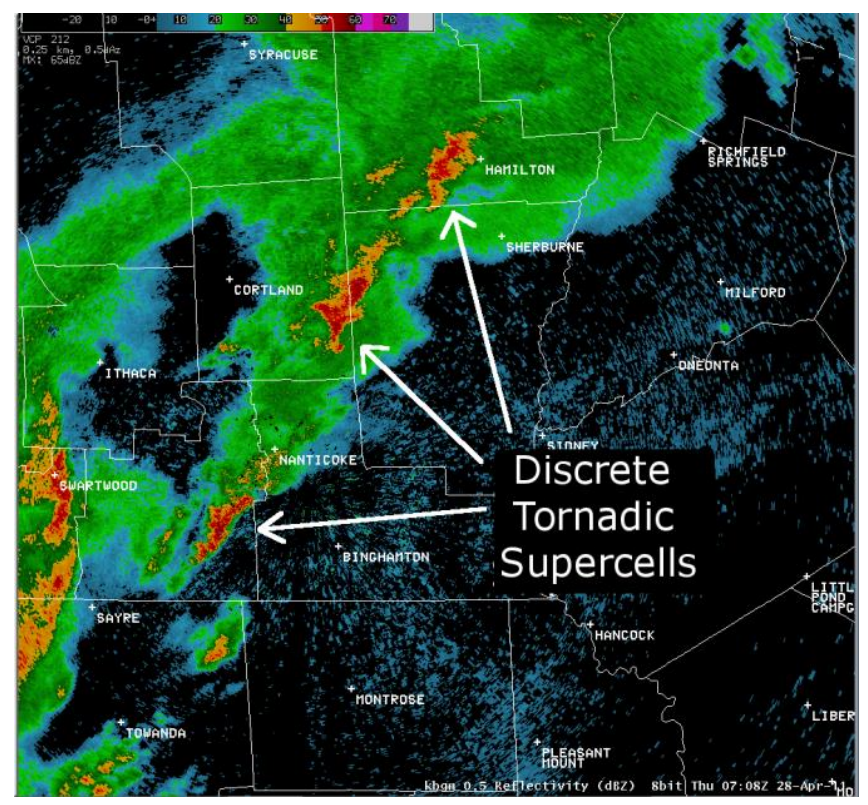

Figure 20. A $0.5^{\circ}$ reflectivity imagery from the Binghamton WSR88D at 0708 UTC 28 April 2011. Each of the three annotated supercells produced a tornado at some point during the event.

\section{Verification}

\section{a. Methods}

All 81 severe and convective flash flood events occurring in the WFO BGM CWA from April 2011 through August 2013 were examined. For each event, data from the local severe weather database corresponding to the event were entered into the checklist to find associated historical analogs. Using these methods, the event being tested was always returned as the number one analog because it would necessarily return

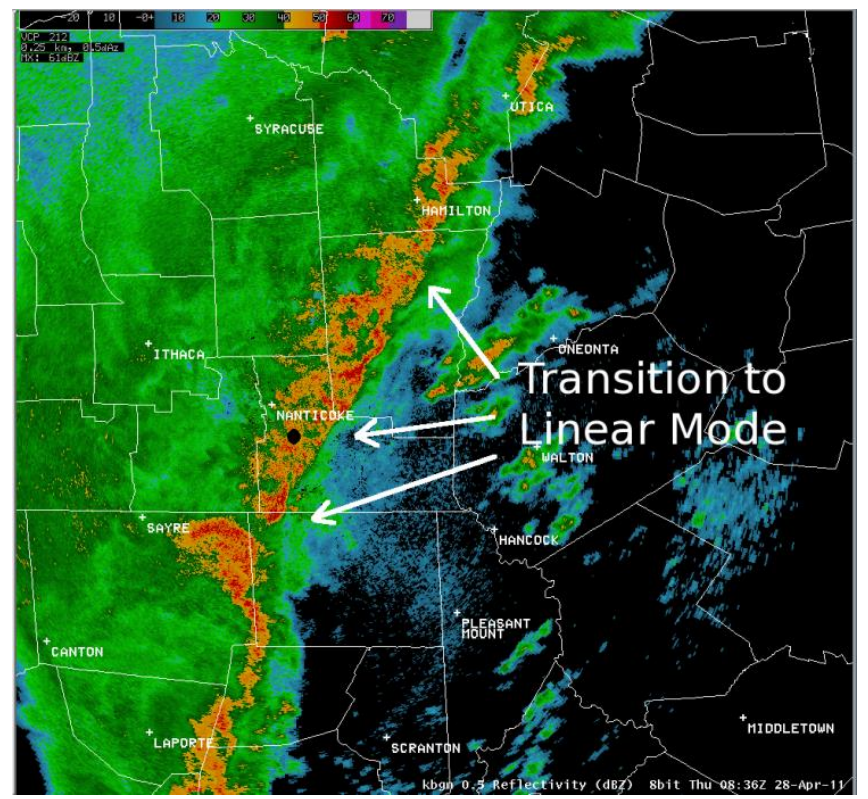

Figure 21. Same as Fig. 20, except at 0836 UTC.

a perfect analog score. Analogs 2-5 were events that the algorithm determined were "most similar" based on parameters in the database. Each case was therefore compared with four historical analogs.

Values for the number of severe weather and flash flood reports associated with the tested and analog events were derived from local storm reports issued by WFO BGM and archived in the National Climatic Data Center's Storm Data publication. Severe weather reports included wind gusts $\geq 25.7 \mathrm{~m} \mathrm{~s}^{-1}$ ( $50 \mathrm{kt}$ or 58 $\mathrm{mph}$ ), hail $\geq 2.54-\mathrm{cm}$ ( $1 \mathrm{in}$ ) in diameter, or tornadoes.

An assessment of the quality of the analogs returned by the checklist was performed in three ways. First, correlations were calculated between the CAPE and bulk shear associated with the 81 test events and corresponding values of those parameters associated with the best and fourth-best analogs. Next, the convective mode of each test event was compared to the convective mode of the corresponding analogs. Finally, the number of severe weather reports associated with each test event was compared with the number of reports associated with the corresponding analogs.

Comparison of the convective modes required that each test event and each analog be categorized. Categorizing the mode of a convective event is often quite difficult (Smith et al. 2012), as the mode may change during the event, and mixed modes are quite common (e.g., a discrete supercell may occur along with a convective line). As such, this process was somewhat subjective. In all cases, events were categorized based on 
the primary mode associated with severe weather occurrence.

Three categories for convective mode were identified based on examination of radar animations from each event: linear, discrete, and multicellular cluster. The linear category was subdivided into solid lines, broken lines, and short lines. A test event was considered to be a match with its corresponding analog if both the test and analog event were categorized as linear or if both were categorized as discrete. [An event featuring discrete pulse storms matched with an analog featuring discrete supercells would have been designated as a non-match; however, this never occurred]. A non-match occurred when an event categorized as "discrete" was paired with a solid or broken line. For all other types of pairings, the ambiguity associated with distinguishing between categories resulted in a non-definitive classification. For example, clusters of multicellular storms often contain embedded short lines of convection. Therefore, a test event with a convective mode classified as a "short line" paired with a "multicellular cluster" analog resulted in a "non-definitive" designation. This methodology was devised in order to only consider test-analog pairs that were clearly well-matched or clearly mismatched for verification.

One factor that should be considered when comparing the number of severe weather reports associated with test events versus historical analogs is the longterm trend in severe weather reports in the WFO BGM CWA. Increasing numbers of spotters - along with increased utilization of new technology such as social media-have resulted in an upward trend in severe weather reports over the past decade (Fig. 22). The data indicate that the number of severe weather reports increased rapidly from 2003 to 2008 and has been relatively steady since 2008 . This trend likely resulted in degradation of some of the correlations that will be shown in the next section. For example, a severe weather event with many severe reports from 2012 might be appropriately matched with an equally significant event from 2004. However, the number of severe weather reports from the 2004 event might be misleadingly small.

\section{b. Results}

Previous research has indicated that perhaps the two most fundamental factors that modulate the evolution and intensity of convection are CAPE and vertical wind shear (Weisman and Klemp 1984). As such, the CAPE and vertical wind shear of test cases should be a good match to the CAPE and vertical wind shear of corresponding analogs developed for the purpose of anticipating convective evolution and severe potential. Scatter diagrams comparing values of test-case CAPE and bulk shear versus analog CAPE and bulk shear for the best analog associated with each case are shown in Figs. 23 and 24. The correlations were very large for both parameters $(0.90$ and 0.88 , respectively). Testcase CAPE was within $500 \mathrm{~J} \mathrm{~kg}^{-1}$ of analog CAPE in 71 of the 81 test cases, and test-case bulk shear was within $5.1 \mathrm{~m} \mathrm{~s}^{-1}(10 \mathrm{kt})$ of analog bulk shear in 75 of the 81 test cases. The same data, except using the fourth-best analogs, are shown in Figs. 25 and 26. Again, large correlations were found, though not as large as for the best analogs ( 0.79 and 0.74 for CAPE and bulk shear, respectively). For the fourth analog, test-case CAPE was within $500 \mathrm{~J} \mathrm{~kg}^{-1}$ of analog CAPE in 60 of the 81 test cases, and test-case bulk shear was within $5.1 \mathrm{~m} \mathrm{~s}^{-1}(10 \mathrm{kt})$ of analog bulk shear in 69 of the 81 test cases. These findings, in combination with several other checks and factors included in the analog-finder algorithm, are highly suggestive that the system could produce appropriate analogs based on similarity of large-scale forcing and sounding parameters.

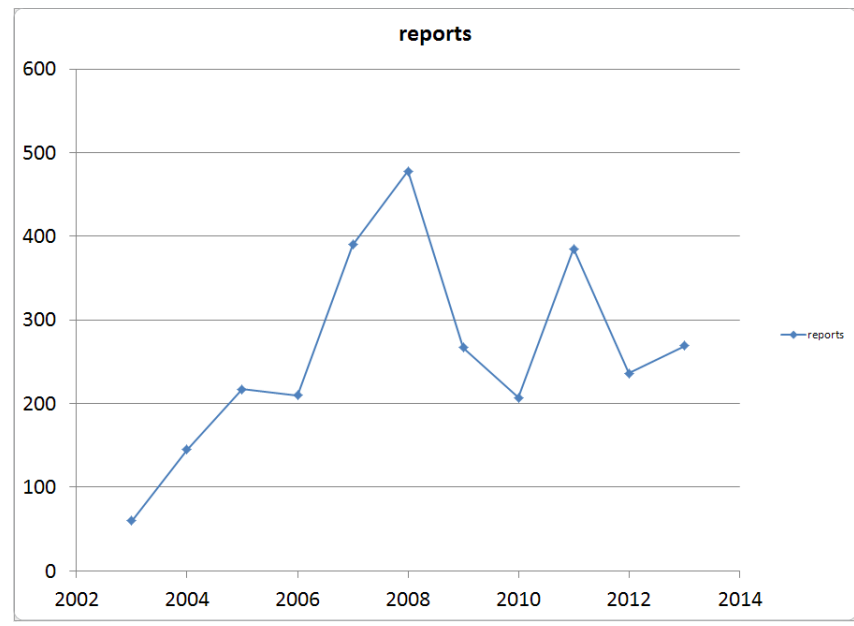

Figure 22. A graph depicting the number of severe weather reports in the BGM CWA ( $y$ axis) per year ( $x$ axis) for the period from 1 January 2003 through 2 September 2013.

Comparisons between the convective modes of the test events in the study versus the modes of the corresponding analogs indicated the following: for the 81 events tested, the number one analog was a match in 40 cases, a non-match in 8 cases, and the comparison was non-definitive in 33 cases. The number two ana- 


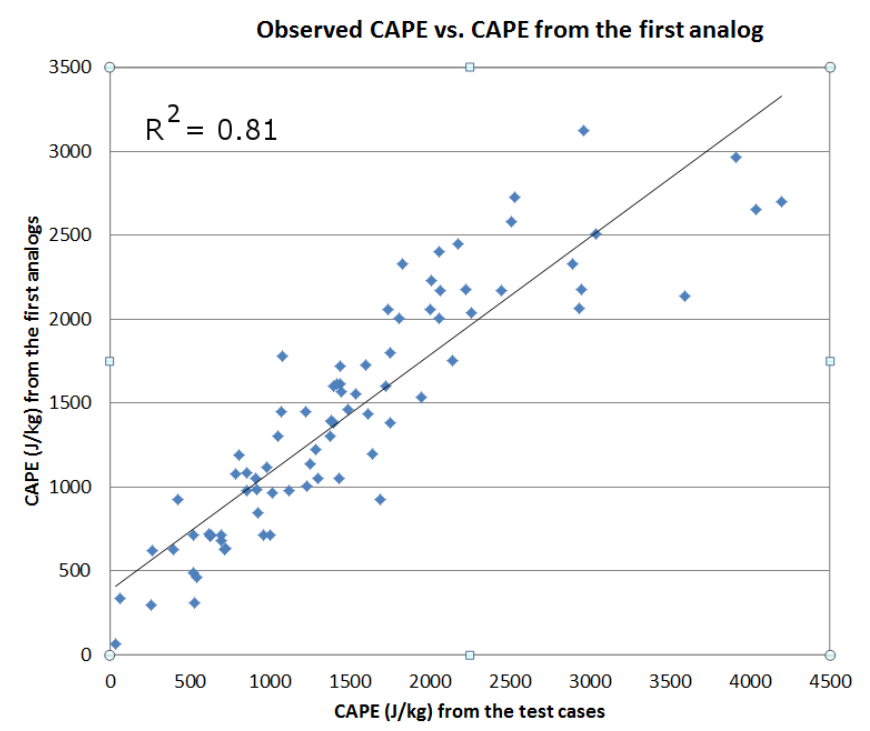

Figure 23. A scatter diagram showing the CAPE $\left(\mathrm{J} \mathrm{kg}^{-1}\right)$ for the 81 test cases ( $x$ axis) versus the CAPE for the corresponding best analogs. A trend line for a linear relationship is annotated.

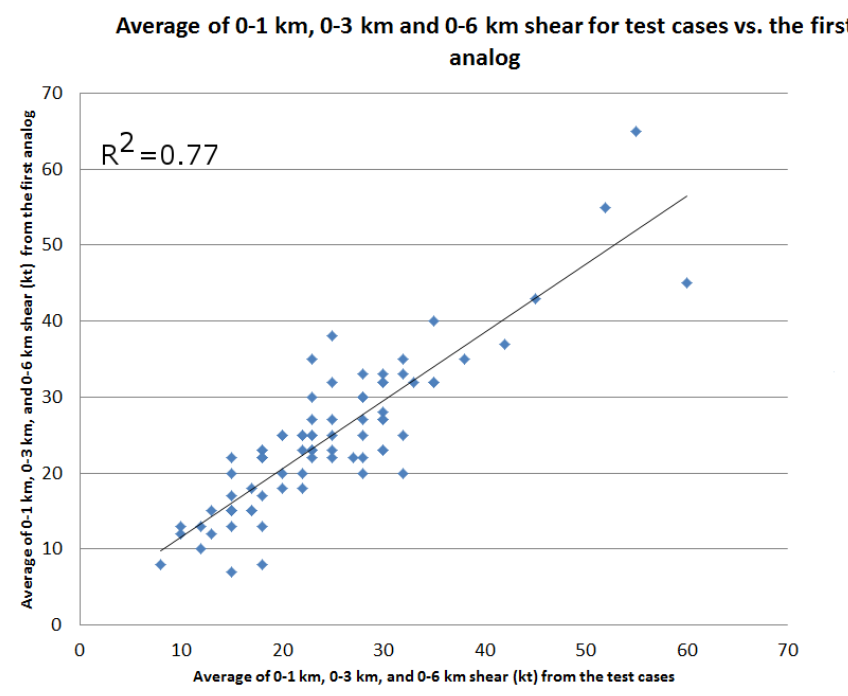

Figure 24. Same as Fig. 23, except for an average of 0-1-km, 0-3$\mathrm{km}$, and 0-6- km shear (kt; multiply by 0.5144 for $\mathrm{m} \mathrm{s}^{-1}$ ).

log was a match in 38 cases, a non-match in 10 cases, and the comparison was non-definitive in 33 cases. An examination of all of the returned analogs in the study (four per case for 81 cases) indicated 146 matches, 37 non-matches, and 141 non-definitive comparisons.

The observed number of severe weather reports for each of the 81 test cases versus the average number of severe weather reports from each test case's four corresponding analogs is shown on the scatter diagram in Fig. 27. The cluster of data points in the lower left part of the graph indicates test cases with a small number of severe weather reports associated with analogs

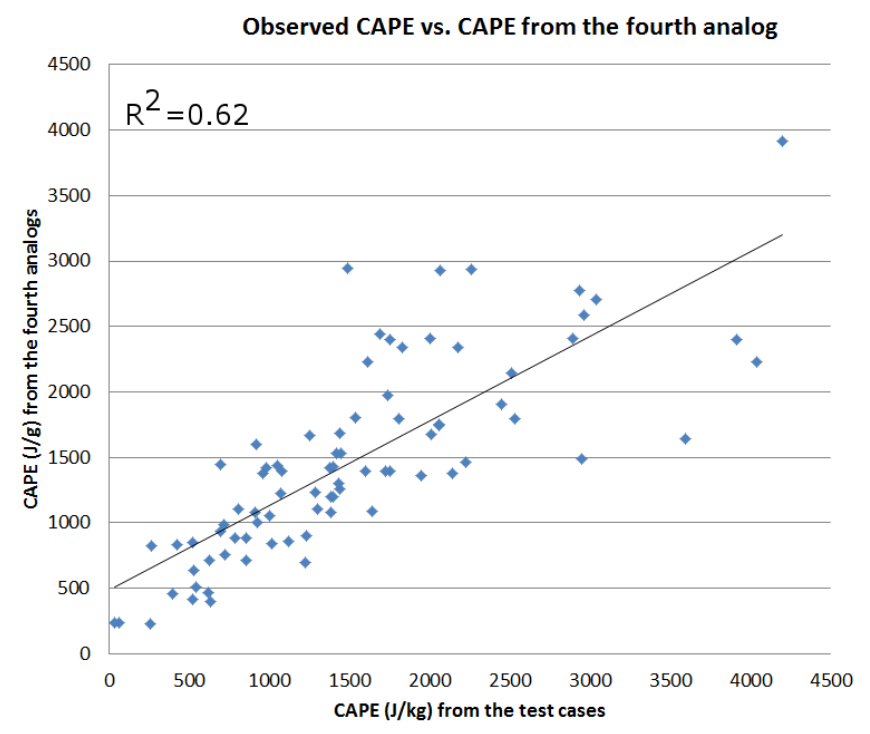

Figure 25. Same as Fig. 23, but for the fourth-best analog.

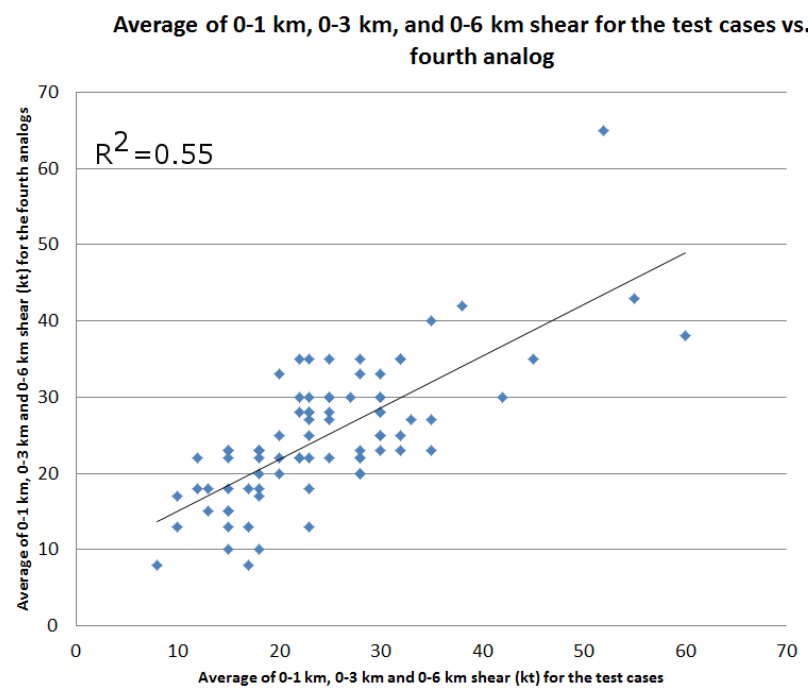

Figure 26. Same as Fig. 24, but for the fourth-best analog.

that also had a small number of severe reports. Cases with a large number of severe weather reports were mostly associated with analogs containing a large number of severe reports. Correlations between the number of test-case severe weather reports versus the number of analog severe weather reports are shown in Fig. 28. Correlations were positive but rather modest for the best analog and the second-best analog, higher for the average of the top two analogs, and highest (0.50) for the average of all four analogs. All of the correlations were statistically significant at the 0.95 level.

In order to test the application's ability to identify significant convective events, characteristics of the analogs associated with various outcomes were exam- 


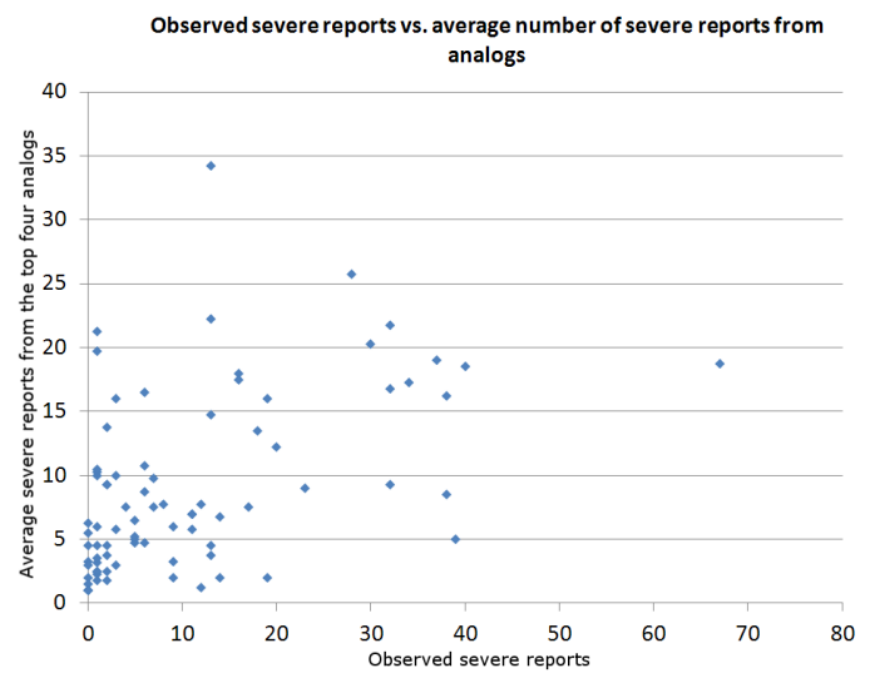

Figure 27. A scatter diagram showing the number of observed severe weather reports for each of 81 test cases ( $x$ axis) versus the average number of reports from the top four analogs for each case ( $y$ axis).

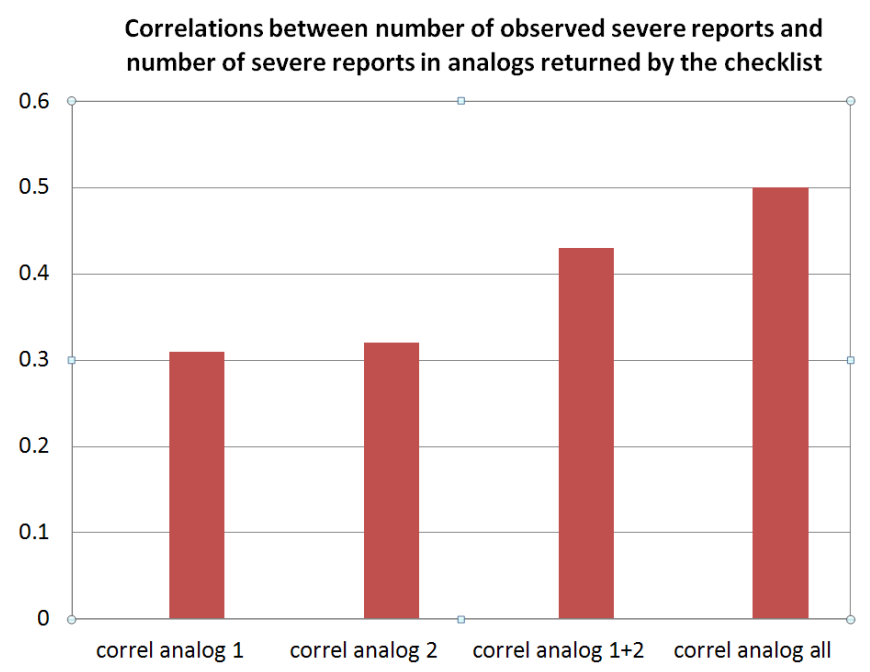

Figure 28. A graph depicting the Pearson product-moment correlation coefficient between the number of observed severe weather reports in the test cases versus the number of severe weather reports in the first analog (correl analog 1), the second analog (correl analog 2), the average number of reports of the first and second analogs (correl analog 1+2), and the average number of reports in the top four analogs (correl analog all) for each event.

ined. For the purposes of this study, "major severe" events were defined as events with at least 30 severe weather reports. Eleven such events have been identified in the BGM CWA since the beginning of 2011, with a median number of 37 reports (Fig. 29). The median number of reports returned from the average of the four analogs associated with those events was 17.25 (Fig. 29). For context, the median number of reports for all 269 events in the severe weather data-

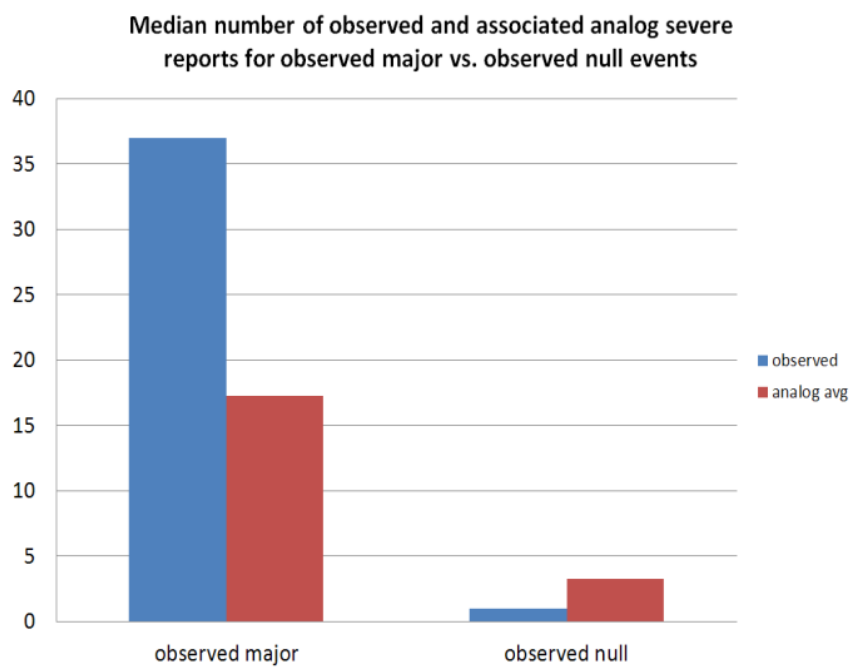

Figure 29. A graph comparing the median number of observed severe weather reports with the median average number of reports from the corresponding analogs for the 11 major events and the 23 null events tested in the verification study.

base is four; therefore, it can be concluded that, when a major event occurs, the checklist generally returns analogs with many more severe weather reports than in a typical event. By contrast, a "null" event was defined as an event with one or fewer severe weather reports. Twenty-three such events are included in the severe weather database since the beginning of 2011. The median number of severe weather reports returned from the average of the corresponding four analogs was 3.25 (Fig. 29). The difference between the number of reports in the analogs associated with major events and the number of reports in the analogs associated with null events is statistically significant at the 0.95 level, according to a Mann-Whitney-Wilcoxon testing procedure (Gibbons 1976).

Ten severe weather events in the BGM CWA have been associated with tornadoes since the beginning of 2011, with a median number of one tornado per event. The median number of tornado reports returned from an average of the top four analogs for those cases was 0.50 , compared to a median of zero for the entire database. Specifically, seven of the 10 tornadic events were associated with at least one tornado-producing analog. For context, $13 \%$ of all of the events in the historical database were associated with at least one tornado, meaning that the probability that at least one tornado would occur at random among the top-four analogs for any test event was 0.43 . The two most significant tornadic events during the test periodeach associated with seven tornadoes-were both flagged as potential tornadic events, with one event 
returning a total of 20 tornadoes in the four analogs, and the other returning a total of three tornadoes.

Ten events in the severe weather database since 2011 were associated with more than five flash flood reports. The number of severe reports associated with these flash flood events ranged from 0 to 32; four of the 10 events were associated with no severe reports. The median number of flash flood reports returned from an average of the top four analogs for those cases was 1.1, compared to a median of zero for the entire database. Specifically, six out of these 10 events were associated with at least one flash flood-producing analog. For context, $25 \%$ of all of the events in the historical database were associated with at least one flash flood report. Therefore, the probability that at least one flash flood report would occur at random among the top-four analogs was 0.68. Based on these numbers, for flash flooding events, the number of flash flood analogs containing at least one flash flood report was no more than what would be expected by chance alone.

The majority of severe weather events in the historical database are associated with more damaging wind reports than large hail reports (Fig. 30). This finding matches results from Hurlbut and Cohen (2014), who also found that severe convective wind is, by far, the predominant severe weather threat for the northeastern United States. As a result, the retrieval system most often returns events dominated by damaging wind, as opposed to large hail. Eleven events were identified from 2011 to 2013 when the ratio of large hail to total severe weather reports was less than 0.10 (with $\geq 5$ total severe reports). In those winddominated cases, the large hail to total severe weather reports for the retrieved analogs was 0.13 , indicating that the retrieval system was returning events that were dominated by damaging winds or tornadoes, as opposed to large hail. Sixteen events were identified when the ratio of large hail versus total severe weather reports was $>0.50$, indicating events with a substantial large hail component. In those cases, the median ratio of large hail to total severe weather reports for the retrieved analog events was 0.33 . This indicates that, for events with a substantial large hail component, the retrieval system still returned events with more wind than hail. However, the analogs for those cases did exhibit a higher large hail to total severe weather report ratio than for the wind-dominated events. Despite this finding, the ratio of large hail to total severe weather reports for the observed wind-dominant events (0.13) was not found to be statistically signifi-

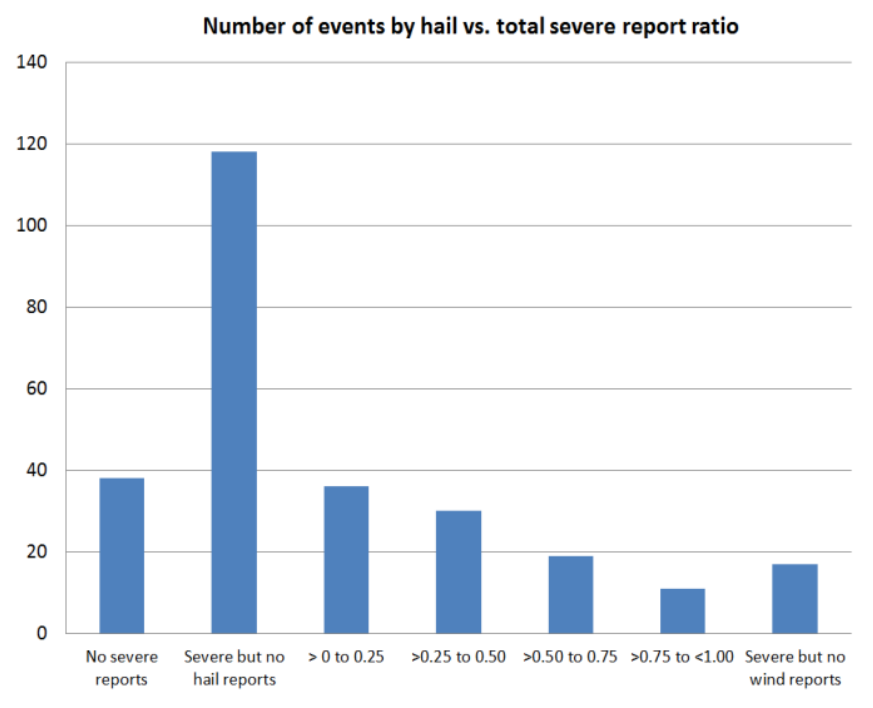

Figure 30. Number of events in the 269 event database partitioned by the ratio of hail reports versus total severe reports. The 38 events with no severe reports were associated with either flash flooding and/or 1.9-cm (0.75 in) diameter hail reports.

cantly less than the same ratio for the hail-dominant events [0.33; at the 0.95 level, using a Mann-WhitneyWilcoxon testing procedure (Gibbons 1976)].

In order to test the application's tendency to produce false alarms, outcomes were examined for cases when analogs indicated the potential for various types of events. For example, when the checklist returns historical analogs with large numbers of severe weather reports, a user could interpret the result as an indication that the checklist is flagging the input event as a potentially major event. For purposes of this study, a "checklist-flagged major" event was defined as when the checklist returned analogs with an average of $\geq 15$ severe weather reports. Twelve such events have occurred in the BGM CWA since the beginning of 2011, with a median of 19.63 reports per analog (Fig. 31). Those events were associated with a median of 29 observed severe weather reports, which is well above the median of four for the entire database (Fig. 31). By contrast, a "checklist-flagged null" event was defined as an event when the checklist returned analogs with an average number of severe reports $<5$. Thirty-two such events have occurred in the BGM CWA since the beginning of 2011, with a median of 2.88 reports per analog (Fig. 31). These events were associated with a median of two observed severe reports, or two less than the median for the entire database (Fig. 31). The difference between the number of observed severe weather reports associated with the "checklist-flagged major" events and the number of observed severe weather reports associated with the "checklist-flagged 
Median number of observed and associated analog severe reports for checklist flagged major events vs. checklist flagged null events

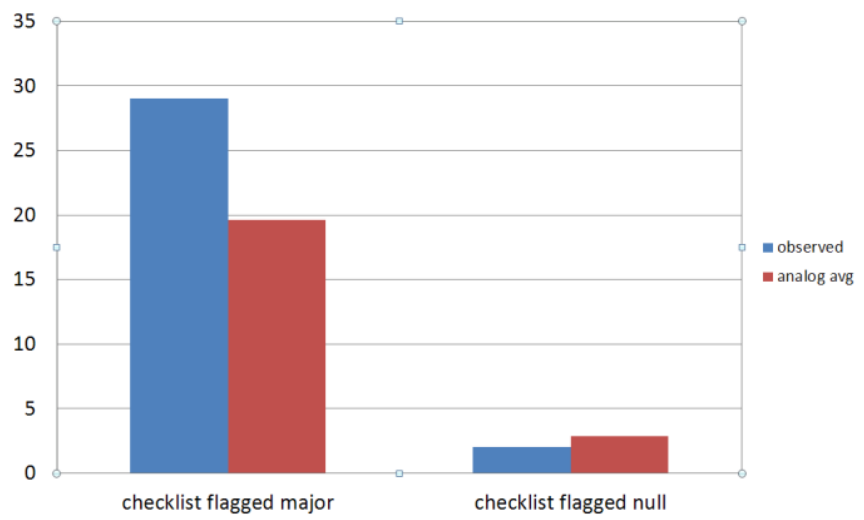

Figure 31. A graph comparing the median number of observed severe weather reports with the median average number of reports from the corresponding analogs for the 12 "checklist-flagged major" severe events tested in the verification study and the 32 "checklist-flagged null" severe events tested in the verification study.

null" events was significant at the 0.95 level, according to a Mann-Whitney-Wilcoxon testing procedure (Gibbons 1976).

A "checklist-flagged tornado" event was defined as any event when the returned analogs were associated with a total of $\geq 4$ tornadoes (an average of $\geq 1$ tornado per analog). There were 10 such events in the BGM CWA since 2011. Four of those events produced at least one tornado. Because only $12 \%$ of all events since the beginning of 2011 have produced at least one tornado, the number of tornadic events corresponding to "checklist-flagged tornado" events was higher than what would be expected by chance.

A "checklist-flagged flash flood" event is defined as any event when the returned analogs were associated with a total of at least four flash floods (an average of at least one flash flood per analog). There were 20 such events in the BGM CWA since 2011. Ten of those events were associated with at least one flash flood report. Because only $32 \%$ of all events since the beginning of 2011 were associated with at least one flash flood, the number of flooding events that were also "checklist-flagged flood" events was above what would be expected by chance.

"Checklist-flagged wind-dominant" events were defined as any case when returned analogs were associated with a large hail to total severe weather report ratio of less than 0.20 . Twenty-one such cases have been identified since 2011, with an observed median ratio of large hail reports to total severe weather reports of 0.04 . "Checklist-flagged hail-dominant" events were defined as cases when the checklist returned analogs associated with a large hail to total severe weather report ratio of greater than 0.50 . Sixteen such cases were identified, with an observed median ratio of large hail reports to total severe weather reports of 0.45 . The difference between the ratios of large hail to total severe reports for the "checklist-flagged wind-dominant" versus "checklistflagged hail-dominant" cases was significant at the 0.95 level, according to a Mann-Whitney-Wilcoxon testing procedure (Gibbons 1976).

\section{Summary and discussion}

This paper describes an operational severe weather checklist developed at WFO BGM. The checklist contains two sections: a traditional severe weather parameter data entry section and a historical analog retrieval section. The best analogs are retrieved based on a comparison of parameter values entered into the checklist with corresponding values of the same parameters from a database of historical severe weather events. An example is shown of a major severe weather event that featured many severe weather reports, including several tornadoes. In this case, analogs returned for the event featured large numbers of severe weather reports, along with several tornadoes, indicating the potential for a major event with tornadoes.

The analog retrieval system shown in this study works by matching input events to potential analogs contained in a historical database, based on the similarity of the large-scale weather pattern and parameter values associated with representative soundings. Historical events are only considered as potential analogs if the surface weather pattern matches the pattern associated with the input event. Results from a verification study on the similarity between three years of test events and corresponding analogs returned by the system indicated large correlations between the test case versus analog CAPE and bulk shear values. These findings indicated that the system was successfully performing its primary function-identifying analogs based on the similarity of both the synoptic weather pattern and parameter values associated with representative soundings.

In order to test whether analogs identified by this system have utility for anticipating convective evolution and severity, additional tests were run on the data. It was found that the convective mode of test events was a match with the mode of corresponding analogs more often than a non-match; however, in many cases 
the comparison was non-definitive. Statistically significant, positive correlations were found between the number of severe weather reports in the test cases and the number of severe weather reports in the corresponding analogs. The number of severe reports in the test cases correlated more strongly to the average number of severe reports from all four analogs than to the number of severe reports from any individual analog. This finding indicates the importance of considering results from multiple analogs when forecasting severe weather potential. However, even the highest of these correlations (0.50) indicated that only $25 \%$ of the variation in the number of severe reports within the test-case dataset were being predicted by the analogs. The upward trend in the number of severe reports described in the methodology section likely contributed to these modest correlations. In addition, these results imply that there are limits to the ability of analogs, as determined by this system, to predict the magnitude of anticipated severe convective events. For the system described in this paper, some of these limitations include 1) the relatively small number of cases in the database available as potential analogs (fewer than $300)$, 2) errors associated with approximations involved with producing soundings that represent the input events, 3) errors associated with using a small number of parameters to describe the large-scale weather pattern, and 4) the natural variability across all scales that would keep any case from being a perfect analog to the current environment.

Despite the limitations discussed above, results from this study indicated that tested events defined as "major" typically returned analogs with many more severe reports than tested events defined as "null." This finding suggests that the checklist can help forecasters discriminate between major and null events. It should be noted when interpreting these results that all of the tested and analogs events in this study included at least one severe weather report or at least one 1.91$\mathrm{cm}(0.75 \mathrm{in})$ diameter hail report or at least one flash flood report. In this study, the criterion for a "null" event was one or fewer severe reports. As a result, some "null" events contained a single severe weather report, some contained only reports of $1.91-\mathrm{cm}(0.75$ in) diameter hail, and some contained only flash flood reports; however, all events were associated with at least one report. The decision to eliminate events associated with no reports of any kind may be considered a weakness in the study, but it is hypothesized that a set of convective cases with no reports likely would yield analogs with characteristics that are quite similar to the analogs for the null cases as defined in this study.

Tornadic events returned analogs with more tornadoes than would be expected by random. Likewise, input events with tornadic analogs were more likely to be tornadic than would be expected by random. These findings indicate that the analog retrieval system provides useful guidance on the potential for tornadoes.

The application described in this paper was initially developed to aid forecasters with anticipating severe convective potential, without regard to convective flash flooding. The potential for using the system to anticipate flash flooding was somewhat of an afterthought; however, tests on the utility for flash flooding were included in this study. In general, the results were less conclusive than for severe convection. For example, flash flood events returned analogs with at least one flash flood at about the rate that would be expected by random. However, the median number of flash floods in these analogs was well above the median for the entire database. In addition, flash flood analogs were more likely to be associated with observed flash flooding than would be predicted by random.

The system's ability to help forecasters discriminate between severe weather events dominated by wind versus large hail also was tested in this study. It was found that the analogs appear to be biased toward wind reports over large hail reports. Additionally, it was found that analogs associated with wind-dominated events contained fewer large hail reports than analogs associated with hail-dominated events, although that difference was not found to be statistically significant. Checklist-flagged, wind-dominant events were associated with lower ratios of large hail to total severe weather reports than checklist-flagged, haildominant events, and that finding was statistically significant. These results indicate that the system may provide useful guidance for discriminating between wind-dominated versus large hail-dominated events; however, it appears that the output should be used with caution for that purpose.

One useful feature of the checklist is that it allows forecasters to easily experiment with different parameter values to see how varying the values affect the characteristics of returned analogs. For example, if the degree of instability on a given day is uncertain, forecasters can enter various values of CAPE to see how the amount of instability might affect characteristics of any corresponding severe weather. Likewise, the ef- 
fects of varying other parameters, such as wind shear or moisture, also can be evaluated, and expectations can be refined as the values of the parameters become more certain. Overall, this checklist and analog retrieval system serve to help forecasters set expectations for severe weather events in the WFO BGM CWA. Forecasters at other locations could use a similar system to provide guidance in other regions in the United States.

Acknowledgments. The authors thank National Weather Service meteorologists Michael Jurewicz, Chris Gitro, and Brian Miretzky for providing a review of this manuscript. Two other anonymous reviewers from National Weather Service Eastern Region Headquarters also provided helpful reviews. Finally, three anonymous reviewers provided comments and suggestions that greatly improved the manuscript

\section{APPENDIX A}

\section{Description of the Point System}

The similarity of historical events to input events is determined by a point system. The application runs by comparing each historical event in a local database to the current forecast, with points assigned based on the similarity of each parameter. The historical event with the largest number of points is returned as the number one event in the analog table (Fig. 3). Likewise, the event with the second largest number of points is returned as the second analog, and so on. Over the course of several years of development, the system has been modified based on a combination of results from local and national studies, event verification, and feedback from forecasters. Events are continuously added to the database as they occur. With 269 events in the database as of September 2013, the vast majority of forecasts are now matched with analogs containing very well-matched sounding parameters.

The algorithm considers time of year as a factor to determine analogs. The time-of-year constraint was added based on feedback from forecasters. An argument also can be made for inclusion of time of year based on research by Hart and Grumm (2001), who have found that standardizing parameter anomalies based on time of year is helpful for identifying extreme events. In addition, the time-of-year test indirectly accounts for the magnitude of the temperature gradient associated with the frontal zone, given the tendency for relatively large temperature gradients early or late in the season. Finally, a time-of-year check may also help to account for a tendency for otherwise equal values of maximum CAPE to be more widespread and/or longer lasting during the middle of the severe weather season compared to early or late in the season. Two thousand points are subtracted from a historical event's point total if the time of year is not a match, effectively removing the event from consideration as a potential analog. Table A1 summarizes the criteria for determining whether a current forecast is a match with a historical event, based on time of year.

Table A1. Months with corresponding months considered to be a "time of year" match by the analog retrieval algorithm.

\begin{tabular}{|l|l|}
\hline $\begin{array}{l}\text { Current } \\
\text { Month }\end{array}$ & Corresponding “Time of Year” Matching Months \\
\hline January & November, December, January, February, March \\
\hline February & January, February, March, April \\
\hline March & January, February, March, April \\
\hline April & February, March, April, May \\
\hline May & April, May, June \\
\hline June & May, June, July \\
\hline July & June, July, August \\
\hline August & July, August, September \\
\hline September & August, September, October, November \\
\hline October & September, October, November, December \\
\hline November & September, October, November, December \\
\hline December & October, November, December, January, February \\
\hline
\end{tabular}

CAPE, CIN, lapse rates, bulk shear, SRH, dewpoint depression, precipitable water, and height falls have points that are assigned to a historical event based on the difference between the input and historical values or on the ratio between input and historical values. Details are shown in Table A2.

Finally, the surface weather pattern must be a match. Possible patterns are a 1) progressive cold front/trough, 2) east-west warm front/stationary front, 3) closed upper low, and 4) weak forcing/other. If the surface weather pattern is not a match, 2000 points are subtracted to ensure that the case is removed from consideration.

The data used in the program are updated via a spreadsheet and then saved as a comma-delimited file. A PHP script reads the file and compares the values in the file with the input data. The PHP script produces the final web page with the top five analogs and links to the appropriate data.

\section{APPENDIX B}

\section{Thresholds for the Banners in the Checklist}

The following thresholds were determined from local, mostly unpublished studies:

- For "a significant cool-season convective squall line:" CAPE between 100 and $800 \mathrm{~J} \mathrm{~kg}^{-1}$, surface-700-hPa lapse rate $>6.5^{\circ} \mathrm{C} \mathrm{km}^{-1}, 0-3-\mathrm{km}$ shear $\geq 20.6 \mathrm{~m} \mathrm{~s}^{-1}(40$ $\mathrm{kt}$ ), 0-6-km shear $\geq 25.7 \mathrm{~m} \mathrm{~s}^{-1}$ (50 kt), direction of the 0 $3-\mathrm{km}$ shear vector $\left\langle 270^{\circ}, 12\right.$-h 500 -hPa height falls $>40$ $\mathrm{m}$, and surface weather pattern is a cold front. 
Table A2. Parameters and corresponding details on assignment of points for historical analog retrieval.

\begin{tabular}{|c|c|c|c|}
\hline Parameter & $\begin{array}{l}\text { Points assigned based on difference in } \\
\text { values between current and historical event }\end{array}$ & $\begin{array}{l}\text { Points assigned based on ratio } \\
\text { between current and historical event }\end{array}$ & Other points \\
\hline CAPE & $\begin{array}{l}\text { If current CAPE is }<500 \mathrm{~J} \mathrm{~kg}^{-1} \text { : } \\
\text { - } 15 \text { points if difference is }<300 \\
\text { - } 8 \text { points if difference is } 300-500 \\
\text { - } 0 \text { points if difference is } 500-700 \\
\text { - Otherwise }-50 \text { points }\end{array}$ & $\begin{array}{l}\text { If current CAPE is } \geq 500 \mathrm{~J} \mathrm{~kg}^{-1} \text { : } \\
\text { - } 15 \text { points for a ratio of } 0.8-1.2 \\
\text { - } 8 \text { points for a ratio of } 1.2-1.4 \text { or } 0.7- \\
0.8 \\
\text { - } 0 \text { points for a ratio of } 1.4-1.5 \text { or } 0.6- \\
0.7 \\
-10 \text { points for a ratio of } 1.5-2.0 \text { or } \\
0.5-0.6 \\
\text { - Otherwise }-50 \text { points }\end{array}$ & $\begin{array}{l}8 \text { additional points are } \\
\text { awarded if both current and } \\
\text { historical event have CAPE } \\
>2000 \mathrm{~J} \mathrm{~kg}^{-1} \text { or }<500 \mathrm{~J} \mathrm{~kg}^{-1}\end{array}$ \\
\hline Convective inhibition & $\begin{array}{l}\text { - } 2 \text { points if difference is }<5 \mathrm{~J} \mathrm{~kg}^{-1} \\
\text { - } 0 \text { points if difference } 5-15 \mathrm{~J} \mathrm{~kg}^{-1} \\
\text { - }-4 \text { points if difference is }>15 \mathrm{~J} \mathrm{~kg}^{-1}\end{array}$ & None & None \\
\hline 950-700-hPa lapse rate & $\begin{array}{l}\text { - } 5 \text { points if difference is }<1^{\circ} \mathrm{C} \mathrm{km}^{-1} \\
\text { - } 2 \text { points if difference is } 1-2^{\circ} \mathrm{C} \mathrm{km}^{-1} \\
\text { - } 0 \text { points if difference is } 2-3^{\circ} \mathrm{C} \mathrm{km}^{-1} \\
\text { - Otherwise }-10 \text { points }\end{array}$ & None & $\begin{array}{l}4 \text { additional points are } \\
\text { awarded if both current and } \\
\text { historical event have lapse } \\
\text { rate }>9^{\circ} \mathrm{C} \mathrm{km}^{-1} \text { or }<3^{\circ} \mathrm{C} \mathrm{km}^{-1}\end{array}$ \\
\hline 700-500-hPa lapse rate & $\begin{array}{l}\text { - } 5 \text { points if difference is }<1^{\circ} \mathrm{C} \mathrm{km}^{-1} \\
\text { - } 2 \text { points if difference is } 1-2^{\circ} \mathrm{C} \mathrm{km}^{-1} \\
\text { - Otherwise } 0 \text { points }\end{array}$ & None & None \\
\hline $\begin{array}{l}\text { 0-1-km storm relative } \\
\text { helicity }\end{array}$ & $\begin{array}{l}\text { If current helicity is } \leq 75 \mathrm{~m}^{2} \mathrm{~s}^{-2} \text { : } \\
\text { - } 4 \text { points if difference is }<30 \\
\text { - } 2 \text { points if difference is } 30-60 \\
\text { - } 0 \text { points if difference is } 60-75 \\
\text { - Otherwise -50 points }\end{array}$ & $\begin{array}{l}\text { If current helicity is }>75 \mathrm{~m}^{2} \mathrm{~s}^{-2}: \\
\text { - } 4 \text { points for a ratio of } 0.8-1.2 \\
\text { - } 0 \text { points for a ratio of } 1.2-2.0 \text { or } 0.4- \\
0.8 \\
-4 \text { points for a ratio of } 2.0-3.0 \text { or } 0.2- \\
0.4 \\
\text { - Otherwise }-50 \text { points }\end{array}$ & $\begin{array}{l}-8 \text { additional points are } \\
\text { awarded if both current } \\
\text { and historical helicity are } \\
\text { both }>150 \mathrm{~m}^{2} \mathrm{~s}^{-2} \\
\text { - } 4 \text { additional points if both } \\
\text { below } 50 \text {. }\end{array}$ \\
\hline $\begin{array}{l}\text { 0-1- and 0-3-km bulk } \\
\text { shear }\end{array}$ & $\begin{array}{l}\text { - } 10 \text { points if difference is }<2.6 \mathrm{~m} \mathrm{~s}^{-1}(<5 \mathrm{kt}) \\
\text { - } 6 \text { points if difference is } 2.6-5.1 \mathrm{~m} \mathrm{~s}^{-1}(5-10 \\
\mathrm{kt}) \\
\text { - } 0 \text { points if difference is }>5.1-10.3 \mathrm{~m} \mathrm{~s}^{-1} \\
(>10-20 \mathrm{kt}) \\
\text { - Otherwise }-10 \text { points }\end{array}$ & None & None \\
\hline 0-6-km bulk shear & $\begin{array}{l}\text { - } 10 \text { points if difference is }<2.6 \mathrm{~m} \mathrm{~s}^{-1}(<5 \mathrm{kt}) \\
\text { - } 6 \text { points if difference is } 2.6-7.7 \mathrm{~m} \mathrm{~s}^{-1}(5-15 \\
\mathrm{kt}) \\
\text { - } 0 \text { points if difference is }>7.7-12.9 \mathrm{~m} \mathrm{~s}^{-1} \\
(>15-25 \mathrm{kt}) \\
\text { - Otherwise }-10 \text { points }\end{array}$ & None & None \\
\hline $\begin{array}{l}\text { Direction of the } 0-3-\mathrm{km} \\
\text { shear vector }\end{array}$ & $\begin{array}{l}\text { - } 10 \text { points if difference is } \leq 20 \text { degrees } \\
\text { - } 5 \text { points if the difference is }>20 \text { degrees to } \\
40 \text { degrees } \\
\text { - Otherwise }-5 \text { points }\end{array}$ & None & None \\
\hline $\begin{array}{l}\text { Equilibrium storm } \\
\text { relative flow }\end{array}$ & $\begin{array}{l}\text { - } 3 \text { points if difference is } \leq 5.1 \mathrm{~m} \mathrm{~s}^{-1}(\leq 10 \mathrm{kt}) \\
\text { - } 1 \text { point if difference is }>5.1-10.3 \mathrm{~m} \mathrm{~s}^{-1} \\
(>10-20 \mathrm{kt})\end{array}$ & None & None \\
\hline $\begin{array}{l}\text { Maximum dewpoint } \\
\text { depression from } 700- \\
500 \mathrm{hPa}\end{array}$ & $\begin{array}{l}\text { - } 8 \text { points if difference is }<5^{\circ} \mathrm{C} \\
\text { - } 4 \text { points if difference is } 5^{\circ} \mathrm{C} \text { to }<10^{\circ} \mathrm{C} \\
\text { - } 2 \text { points if the difference is } 10^{\circ} \mathrm{C} \text { to }<20^{\circ} \mathrm{C} \\
\text { - Otherwise } 0 \text { points }\end{array}$ & None & None \\
\hline Precipitable water & $\begin{array}{l}\text { If the current precipitable water is } \leq 1.9 \mathrm{~cm} \\
(\leq 0.75 \mathrm{in}) \text { : } \\
-6 \text { points if difference is }<0.25 \mathrm{~cm}(<0.1 \mathrm{in}) \\
-4 \text { points if difference is } 0.25-0.76 \mathrm{~cm}(0.1- \\
0.3 \text { in) } \\
2 \text { points if difference is } 0.76-1.5 \mathrm{~cm}(0.3- \\
0.6 \text { in }) \\
- \text { Otherwise }-50 \text { points }\end{array}$ & $\begin{array}{l}\text { If the current precipitable water is }>1.9 \\
\mathrm{~cm}(>0.75 \text { in): } \\
-6 \text { points for a ratio of } 0.8-1.2 \\
\text { - } 4 \text { points for a ratio of } 1.2-1.6 \text { or } 0.6- \\
0.8 \\
-2 \text { points for a ratio of } 1.6-2.0 \text { or } 0.4- \\
0.6 \\
-0 \text { points for a ratio of } 2.0-2.5 \text { or } 0.2- \\
0.4 \\
\text { - Otherwise }-50 \text { points }\end{array}$ & $\begin{array}{l}6 \text { additional points are } \\
\text { awarded if both current and } \\
\text { historical event are }>5.08 \mathrm{~cm} \\
\text { ( }>2.0 \text { in) or }<2.54 \mathrm{~cm}(<1.0 \\
\text { in) }\end{array}$ \\
\hline
\end{tabular}


- For "a significant warm-season convective squall line:" CAPE $>2000 \mathrm{~J} \mathrm{~kg}^{-1}, 0-3-\mathrm{km}$ shear $\geq 15.4 \mathrm{~m} \mathrm{~s}^{-1}$ (30 kt), $0-3-\mathrm{km}$ shear direction $>240^{\circ}$, the difference between the $0-6-\mathrm{km}$ and $0-3-\mathrm{km}$ shear is $\leq 5.1 \mathrm{~m} \mathrm{~s}^{-1}$ (10 kt), and the storm-relative flow at the equilibrium level is $<23.1$ $\mathrm{m} \mathrm{s}^{-1}$ (45 kt).

- For "tornadic supercells:" CAPE between 800 and 2500 $\mathrm{J} \mathrm{kg}^{-1}, 0-1-\mathrm{km}$ shear $\geq 10.3 \mathrm{~m} \mathrm{~s}^{-1}$ (20 kt), 0-1-km SRH $\geq 100 \mathrm{~m}^{2} \mathrm{~s}^{-2}, 0-3-\mathrm{km}$ shear $\geq 15.4 \mathrm{~m} \mathrm{~s}^{-1}$ (30 kt), 0-6-km shear $\geq 20.6 \mathrm{~m} \mathrm{~s}^{-1}(40 \mathrm{kt})$, and forcing is a warm front or cold front.

\section{REFERENCES}

Beebe, R. G., 1958: Tornado proximity soundings. Bull. Amer. Meteor. Soc., 39, 195-201.

Benjamin, S. G., and Coauthors, 2004: An hourly assimilation-forecast cycle: The RUC. Mon Wea. Rev., 132, 495-518, CrossRef. , and _ 2007: From the radar-enhanced RUC to the WRF-based Rapid Refresh. Preprints, 22nd Conf. on Weather Analysis and Forecasting/18th Conf. Numerical Weather Prediction, Park City, UT, Amer. Meteor. Soc., J3.4. [Available online at ams.confex.com/ams/ 22WAF18NWP/techprogram/paper_124827.htm.]

Black, T. L., 1994: The new NMC mesoscale Eta model: Description and forecast examples. Wea. Forecasting, 9, 265-278, CrossRef.

Brooks, H. E., C. A. Doswell III, and J. Cooper, 1994: On the environments of tornadic and nontornadic mesocyclones. Wea. Forecasting, 9, 606-618, CrossRef.

Craven, J. P., and H. E. Brooks, 2004: Baseline climatology of sounding derived parameters associated with deep moist convection. Natl. Wea. Dig., 28, 13-24. [Available online at www.nwas.org/digest/papers/2004/ Vol28/Pg13-Craven.pdf.]

Dial, G. L., J. P. Racy, and R. L. Thompson, 2010: Shortterm convective mode evolution along synoptic boundaries. Wea. Forecasting, 25, 1430-1446, CrossRef.

Doswell, C. A., III, and D. M. Schultz, 2006: On the use of indices and parameters in forecasting severe storms. Electronic J. Severe Storms Meteor., 1 (3), 1-22. [Available online at www.ejssm.org/ojs/index.php/ ejssm/article/view/11/10.]

, H. E. Brooks, and R. A. Maddox, 1996: Flash flood forecasting: An ingredients-based methodology. Wea. Forecasting, 11, 560-581, CrossRef.

Evans, M., 2010: an examination of low CAPE/high shear severe convective events in the Binghamton, New York county warning area. Natl. Wea. Dig., 34, 129-144. [Available online at www.nwas.org/digest/papers/2010/ Vol34No2/Pg129-Evans.pdf.] and R. Murphy, 2008: A proposed methodology for reconciling high-resolution numerical modeling guidance with pattern recognition to predict lake-effect snow. Electronic J. Operational Meteor., 9 (2), 1-55. [Available online at www.nwas.org/ej/pdf/2008-EJ2.pdf.]

Fawbush, E. J., and R. C. Miller, 1954: The types of airmasses in which North American tornadoes form. Bull. Amer. Meteor. Soc., 35, 154-165.

Gibbons, J. D., 1976: Nonparametric Methods for Quantitative Analysis. American Sciences Press, 463 pp.

Gordon, J. D., and D. Albert, cited 2012: A comprehensive severe weather forecast checklist and reference guide. National Weather Service, Springfield, MO. [Available online at www.crh.noaa.gov/sgf/?n=severe weather checklist paper.]

Gravelle, C. M., C. E. Graves, J. P. Gagan, F. H. Glass, and M. S. Evans, 2009: Winter weather guidance from regional historical analogs. Preprints, 23rd Conf. on Weather Analysis and Forecasting, Omaha, NE, Amer. Meteor. Soc., JP3.10. [Available online at ams.confex.com/ams/pdfpapers/154201.pdf.]

Hart, R. E., and R. H. Grumm, 2001: Using normalized climatological anomalies to rank synoptic-scale events objectively. Mon. Wea. Rev., 129, 2426-2442, CrossRef.

Hurlbut, M. M., and A. E. Cohen, 2014: Environments of Northeast U.S. severe thunderstorm events from 1999 to 2009. Wea. Forecasting, 29, 3-22, CrossRef.

Jewell, R. E .D., 2010: The Sounding Analog Retrieval System (SARS). Preprints, 25th Conf. on Severe Local Storms, Denver, CO, Amer. Meteor. Soc., 4B.3 [Available online at ams.confex.com/ams/pdfpapers/ 176260.pdf.]

Johns R. H., and C. A. Doswell III, 1992: Severe local storms forecasting. Wea. Forecasting, 7, 588-612, CrossRef.

Kain, J. S., S. J. Weiss, J. J. Levit, M. E. Baldwin, and D. R. Bright, 2006: Examination of convection-allowing configurations of the WRF model for the prediction of severe convective weather: The SPC/NSSL Spring Program 2004. Wea. Forecasting. 21, 167-181, CrossRef.

, and Coauthors, 2008: Some practical considerations regarding horizontal resolution in the first generation of operational convection-allowing NWP. Wea. Forecasting, 23, 931-952, CrossRef.

LaPenta, K. D., G. J. Maglaras, J. W. Center, S. A. Munafo, and C. J. Alonge, 2002: An updated look at some severe weather forecast parameters. NWS ER Tech. Attach. 2002-01, 22 pp. [Available online at www.erh.noaa.gov/er/hq/ssd/erps/ta/ta2002-01.pdf.]

Lombardo, K. A., and B. A. Colle, 2010: The spatial and temporal distribution of organized convective structures over the Northeast and their ambient conditions. Mon. Wea. Rev., 138, 4456-4474, CrossRef. 
Mahoney, E. A., and T. A. Niziol, 1997: BUFKIT: A software application toolkit for predicting lake-effect snow. Preprints, 13th Int. Conf. on Interactive Information and Processing Systems for Meteorology, Oceanography, and Hydrology, Long Beach, CA, Amer. Meteor. Soc., 388-391. [Available online at www.erh.noaa.gov/buf/respap1.htm.]

Rasmussen, E. N., 2003: Refined supercell and tornado forecast parameters. Wea. Forecasting, 18, 530-535, CrossRef.

Rogers, E., T. Black, B. Ferrier, Y. Lin, D. Parrish, and G. DiMego, 2001: Changes to the NCEP Meso Eta Analysis and Forecast System: Increase in resolution, new cloud microphysics, modified precipitation assimilation, modified 3DVAR analysis. NOAA/NWS Tech. Procedures Bull. 488, 21 pp. [Available online at www.emc.ncep.noaa.gov/mmb/mmbpll/eta12tpb/.]

Smith, B. T., R. L. Thompson, J. S. Grams, C. Broyles, and H. E. Brooks, 2012: Convective modes for significant severe thunderstorms in the contiguous United States. Part I: Storm classification and climatology. Wea. Forecasting, 27, 1114-1135, CrossRef.

Thompson, R. L., R. Edwards, J. A. Hart, K. L. Elmore, and P. Markowski, 2003: Close proximity soundings within supercell environments obtained from the Rapid Update Cycle. Wea. Forecasting, 18, 1243-1261, CrossRef.

, B. T. Smith, J. S. Grams, A. R. Dean, and C. Broyles, 2012: Convective modes for significant severe thunderstorms in the contiguous United States. Part II: Supercell and QLCS tornado environments. Wea. Forecasting, 27, 1136-1154, CrossRef.

Troutman, T. W., D. B. Elson, and M. A. Rose, cited 2009: A severe weather threats checklist to determine prestorm environment. National Weather Service, Nashville, TN. [Available online at www.srh.noaa.gov/ohx/ ?n=checklist.]

Weisman, M. L., and J. B. Klemp, 1984: The structure and classification of numerically simulated convective storms in directionally varying wind shears. Mon. Wea. Rev., 112, 2479-2498, CrossRef.

Wetzel, S. W., and J. E. Martin, 2001: An operational ingredients-based methodology for forecasting midlatitude winter season precipitation. Wea. Forecasting, 16, 156-167, CrossRef.

Wheeler, M. M., 2009: Severe weather and weak waterspout checklist in MIDDS. NASA Contractor Report NASA/CR-2009-214760, 16 pp. [Available online at science.ksc.nasa.gov/amu/final-reports/svr-wX-wkshtmidds.pdf.] 